\title{
PROCEEDINGS OF THE \\ BRITISH PHARMACOLOGICAL SOCIETY \\ CLINICAL PHARMACOLOGY SECTION
}

18-20 April 1990

UNIVERSITY OF SHEFFIELD

For oral communications with more than one author, an asterisk (*) denotes the one who presented the work. 


\section{COMMUNICATIONS}

\section{Systolic time intervals by the impedance method; accuracy and correlation with left ventricular function}

\author{
S. H. L. THOMAS* \& S. E. SMITH \\ Division of Pharmacological Sciences and Toxicology, \\ United Medical and Dental School (St Thomas' \\ Campus), London SE1 7EH
}

The effects of drugs on left ventricular contractility can be inferred by the non-invasive measurement of systolic time intervals (Hassan $\&$ Turner, 1983). These include the intervals between the ECG Q wave and the opening (preejection period, PEP) and closure (total electromechanical systole, EMS) of the aortic valve, and the duration of left ventricular ejection (ventricular ejection time, VET). Conventionally, these intervals are measured by three channel recordings of ECG, phonocardiogram, and externally-measured carotid artery pulse waveform (Mechanophonocardiography, MPC). Although accurate, this method is time consuming and may be technically difficult. Alternatively, two channel recordings of the ECG and first derivative impedance cardiogram (dZ/dt) can be used (ECG-dZ/dt method), as the $\mathrm{B}$ and $\mathrm{X}$ deflections correspond to aortic valve opening and closing (Balasubramanian $e t$ al., 1978). This method is simpler and more suitable for computer automation.
To study the accuracy of the ECG-dZ/dt method, triplicate measurements (averaged over $10 \mathrm{~s}$ ) made during supine rest were compared with those made simultaneously by MPC. Results were compared by regression analysis and by calculation of the limits of agreement (Bland \& Altman, 1986).

Correlation coefficients were 0.95 for preejection period (PEP), 0.94 for ventricular ejection time (VET) and 0.89 for the PEP/VET ratio (all $P<0.0001$ ). The immediate repeatability of the two methods was similar. Limits of agreement are shown in Table 1 (mean of 24 pairs $\pm 95 \%$ confidence intervals). Supine ECG-dZ/dt STI measurements were also compared with angiographic left ventricular ejection fraction (LVEF) in 24 patients with coronary artery disease. Significant correlation between LVEF and PEP/VET $(r=0.65, P<$ 0.001 ) was demonstrated, but there was considerable scatter around the line of best fit.

These results indicate close agreement between the two methods, and suggest that measurements made by the $\mathrm{dZ} / \mathrm{dt}$ method are suitable for the non-invasive quantification of systolic time intervals. However the correlation between PEP/VET and LVEF was not as strong as in previous reports (Garrard et al., 1970), and caution is required when inferring ventricular function from these measurements.

Table 1 Agreement between MPC and ECG-dZ/dt derived systolic time intervals

\begin{tabular}{lrrc}
\hline & $P E P(\mathrm{~ms})$ & \multicolumn{1}{c}{$V E T(\mathrm{~ms})$} & $P E P / V E T\left(\times 10^{3}\right)$ \\
\hline Algebraic difference & $2.8 \pm 1.9$ & $5.9 \pm 5.6$ & $14 \pm 14$ \\
Bias (d) & $0.3 \pm 1.4$ & $1.5 \pm 3.4$ & $0 \pm 7$ \\
d - 2 s.d. & $-6.6 \pm 2.5$ & $-14.6 \pm 5.8$ & $-36 \pm 13$ \\
d +2 s.d. & $7.3 \pm 2.5$ & $17.7 \pm 5.8$ & $36 \pm 13$ \\
\hline
\end{tabular}

Balasubramanian, V. et al. (1978). Br. Heart J., 40, 268.

Bland, J. M. \& Altman, D. G. (1986). Lancet, i, 307.
Garrard, G. L. et al. (1970). Circulation, 42, 455.

Hassan, S. \& Turner, P. (1983). Postgrad. med J., 59, 423. 
Haemodynamic effects of various histamine $\mathrm{H}_{2}$-receptor antagonists assessed by noninvasive techniques

H. HINRICHSEN*, A. HALABI, G. HÜBNER \&
W. KIRCH

I. Medizinische Klinik, Christian-AlbrechtsUniversität, Schittenhelmstrasse 12, 2300 Kiel, Federal Republic Germany

In a previous study famotidine appeared to exert negative effects on cardiac performance (Kirch et al., 1989). Therefore the question arose how the older histamine $\mathrm{H}_{2}$-receptor antagonists cimetidine and ranitidine would alter non-invasively measured haemodynamic parameters compared with famotidine. In a randomized placebo-controlled double-blind cross-over designed study 10 healthy volunteers (age $26.5 \pm 2.3$ years; body weight $67.8 \pm$ $9.5 \mathrm{~kg}$; median \pm s.e. mean) were treated orally for 1 week each with cimetidine $800 \mathrm{mg}$ once daily, ranitidine $300 \mathrm{mg}$ (once daily), famotidine $40 \mathrm{mg}$ (once daily), and placebo (once daily). On the first day of therapy and after 1 week of treatment heart rate, blood pressure, mechanocardiography (systolic time intervals; STI), and impedance cardiography (IC) were measured before 2, 6, 12 and $24 \mathrm{~h}$ after administration of the last dose of each drug. For

Kirch, W. et al. (1989). Gastroenterology, 96, 1388. statistics the Friedmann rank variance analysis was used. Heart rate and blood pressure values were not altered by any of the histamine $\mathrm{H}_{2}$ receptor antagonists investigated. There were also no significant differences $(P<0.05)$ in the data of STI and IC comparing cimetidine, ranitidine and placebo treatment. However, with famotidine administration stroke volume in IC was decreased $2 \mathrm{~h}$ after administration compared with baseline values by $-8.8 \pm$ $3.5 \mathrm{~cm}^{3}$ (significant with $P<0.05$ compared with placebo). In the same way cardiac output in IC was decreased $2 \mathrm{~h}$ after famotidine administration by $-0.61 \pm 0.291 \mathrm{~min}^{-1}$ (placebo + $\left.0.28 \pm 0.161 \mathrm{~min}^{-1} ; P<0.05\right)$. In the systolic time intervals only the pre-ejection period/left ventricular ejection time ratio (PEP/LVET) was increased $2 \mathrm{~h}$ after famotidine administration compared with baseline values by +0.019 \pm 0.006 (placebo $-0.003 \pm 0.003 ; P<0.05$ ). Six hours after administration only stroke volume was decreased under famotidine administration compared with placebo.

The observed changes of haemodynamic parameters with famotidine administration confirm that this histamine $\mathbf{H}_{2}$-receptor antagonist exerts negative effects on cardiac performance, whereas for cimetidine and ranitidine such influences could not be shown in the present study.

\section{Comparison of captopril, hydralazine and nifedipine as third drug in hypertensive patients}

E. G. BEVAN*, P. C. WALLER, A. L. HERRICK, S. D. PRINGLE, J. G. FINDLAY, G. D. MURRAY, H. A. CARMICHAEL, J. L. REID, A. R. LORIMER \& G. T. McINNES

Glasgow Blood Pressure Clinic, Western Infirmary, Glasgow G11 6NT

Stepped care therapy based on $\beta$-adrenoceptor blocker and thiazide diuretic remains the conventional approach to the management of hypertension. Choice of third drug is less clear; hydralazine (McAreavey et al., 1984) and nifedipine (Ramsay et al., 1987) have been suggested as suitable options. The aim of this study was to make a direct comparison of these drugs and captopril as third drugs in hypertension.
The antihypertensive, biochemical, and adverse effects of captopril (C) 50-150 mg daily, hydralazine $(\mathrm{H}) \quad 50-200 \mathrm{mg}$ daily, nifedipine sustained-release (N) 40-80 mg daily and placebo $(\mathrm{P})$, were compared in a single-blind, randomized, parallel group study of 160 patients aged 18-65 years with supine systolic blood pressure $(\mathrm{SBP}) \geqslant 140 \mathrm{~mm} \mathrm{Hg}$ or supine diastolic blood pressure $(\mathrm{DBP}) \geqslant 95 \mathrm{~mm} \mathrm{Hg}$ after a minimum of 4 weeks treatment with atenolol $100 \mathrm{mg}$ daily plus bendrofluazide $5 \mathrm{mg}$ daily. Treatment was titrated at 2 week intervals for 6 weeks (target : SBP $<140 \mathrm{~mm} \mathrm{Hg}$ and DBP $<95 \mathrm{~mm} \mathrm{Hg}$ ) and maintained at the final dose for a further 6 weeks. Atenolol and bendrofluazide therapy remained constant.

The principal results are shown in Table 1.

The three active drugs had equal antihypertensive efficacy. Although serum cholesterol concentration fell more in the hydralazine group 
than in the other treatment groups $(P \leq 0.05)$, symptomatic side-effects did not differ significantly between the groups. In blood pressure control and in tolerability, however, there were trends in favour of captopril which may now be considered the choice among the drugs tested.

Table 1

\begin{tabular}{lccccc}
\hline & $P$ & $C$ & $H$ & $N$ & P value \\
\hline Mean change in SBP (mm Hg) & -8.0 & -21.4 & -23.0 & -24.8 & $<0.01$ \\
Mean change in DBP (mmHg) & -1.0 & -12.2 & -11.9 & -9.9 & $<0.01$ \\
BP controlled (\%) & 10 & 33 & 29 & 17 & NS \\
Median change in serum cholesterol (mmol l-1) & +0.2 & -0.2 & -0.8 & -0.2 & $<0.01$ \\
Withdrawn due to adverse effects (\%) & 3 & 15 & 24 & 22 & NS \\
\hline
\end{tabular}

McAreavey, D. et al. (1984). Br. med. J., 288, 106.
Ramsay, L. E. et al. (1987). Postgrad. med. J., 63, 99.
Assessment of MK-467, a peripheral $\alpha_{2}$ adrenoceptor antagonist using intravenous clonidine

\author{
J. B. WARREN*, C. T. DOLLERY, D. \\ SCIBERRAS $^{1} \&$ M. GOLDBERG ${ }^{1}$ \\ Departments of Clinical Pharmacology and \\ Medicine, Royal Postgraduate Medical School, \\ Hammersmith Hospital, London W12 0HS and \\ ${ }^{1}$ Merck Sharp \& Dohme Research Laboratories, \\ New Jersey, USA
}

MK-467, a spirocyclic substituted benzofuroquinilizone, is a potent and competitive $\alpha_{2}$-adrenoceptor antagonist both in vitro and in vivo in animals, which does not cross the blood brain barrier. Initial volunteer studies are consistent with MK-467 being an $\alpha_{2}$-adrenoceptor antagonist. The present study assessed the $\alpha_{2}$-adrenoceptor antagonist activity of MK-467 in vivo in man by measuring its inhibition of the response to the $\alpha_{2}$-adrenoceptor agonist clonidine.

Eight healthy normal male volunteers received oral doses of either 30 or $15 \mathrm{mg}$ of MK-467, or a placebo in a randomized, doubleblind, crossover design. One hour after dosing, $200 \mu \mathrm{g}$ of clonidine were given intravenously over $10 \mathrm{~min}$. Heart rate, blood pressure, salivary flow, sedation, anxiety and physical symptom scores were measured throughout and for $\mathbf{8 h}$ after the clonidine infusion. Venous blood was sampled for plasma growth hormone, adrenaline, noradrenaline, insulin and glucose.

MK-467 was well tolerated. On the placebo day mean (s.e. mean) systolic blood pressure changed from $117 \pm 3$ to $115 \pm 4 \mathrm{~mm} \mathrm{Hg}$ in the first hour, the corresponding figures for the 15 $\mathrm{mg}$ dose were $116 \pm 4$ to $119 \pm 4(\mathrm{NS})$ and for the $30 \mathrm{mg}$ dose $118 \pm 3$ to $122 \pm 3(P<0.01)$. The maximum fall in mean systolic pressure (65 min after clonidine infusion ceased) was not significantly different being 19, 16 and 21 $\mathrm{mm} \mathrm{Hg}$ on placebo, low and high dose of MK467 respectively. Changes in diastolic pressure and heart rate were not significantly different on the 3 study days. In the first hour after tablet ingestion there was no change in mean blood glucose. Clonidine infusion caused a peak increase in mean blood glucose of $13 \%$ from a baseline level of $5.3 \pm 0.2 \mathrm{mmol} \mathrm{l}^{-1}$, which was antagonised by both low and high doses of MK-467 $(P<0.05)$. Clonidine caused a peak fall in plasma insulin from $74 \pm 14$ to $46 \pm 9 \mathrm{iu}$ $1^{-1}$ on the placebo day, an effect antagonised by the high dose of MK-467 $(P<0.05)$.

Clonidine caused marked xerostomia, sedation and increases in plasma growth hormone each of which were not affected by pretreatment with MK-467. During the first hour after tablet ingestion plasma noradrenaline increased $4 \%, 15 \%$ and $18 \%$ after placebo, low and high dose MK-467 (NS). Clonidine reduced plasma noradrenaline levels to $79 \pm 7 \%$ of control at $1 \mathrm{~h}$ post infusion, an effect which was antagonized by low dose MK-467 $(P<$ $0.05)$.

MK-467 inhibited the peripheral effects, but none of the central effects, of $200 \mu \mathrm{g}$ of intravenous clonidine. MK-467 had a small effect on clonidine-induced changes in plasma glucose and insulin, suggesting that peripheral $\alpha_{2}$-adrenoceptors play only a minor role in normal glucose homeostasis. 
A study of the effect of MK-467 on the metabolic responses to exercise in healthy man

D. G. SCIBERRAS*, J. REED ${ }^{1}$, C. ELLIOTT ${ }^{1}$, M. LAKER $^{1}$ \& M. R. GOLDBERG (introduced by J. Haigh)

Merck Sharp \& Dohme Research Laboratories, Neuroscience Research Centre, Terlings Park, Harlow, Essex and ${ }^{1}$ Department of Physiology, University of Newcastle upon Tyne, Newcastle upon Tyne

MK-467 is a potent, selective, competitive inhibitor of $\alpha_{2}$-adrenoceptor sites. The drug's activity is limited to peripheral effects since it does not cross the blood brain barrier. Using MK-467, we investigated the role of $\alpha_{2}$-receptors in mediating effects of exercise in man. Nine healthy, fit, male volunteers (age 19-28 years, mean 21.8) were enrolled in the study following Ethics Committee approval and written informed consent. The study was conducted on 3 days, each separated by a period of at least 14 days. On each study day, after an overnight fast, each subject was given one of three i.v. treatments, two of active drug (Low, L; High, $\mathrm{H}$ ) in ascending order, and one of placebo (P) randomly inserted into the sequence. The i.v. dosing schedule was designed to maintain a steady state plasma concentration of approximately 90 and $440 \mathrm{ng} \mathrm{ml}^{-1}$ (based on receptor affinity and prior kinetic data from human studies suggesting activity). During the infusion, each subject was required to follow a standard, incrementally increasing, near-maximal exercise protocol. Throughout the study period, blood samples were taken for measurement of plasma catecholamines, insulin, glucose and free fatty acids (FFA).

A significant increase in mean plasma noradrenaline (NA) was found immediately prior to exercise on each of the active drug treated days (Table 1) and this difference persisted throughout the period of the exercise when NA generally increased. Adrenaline (A) was unaffected by MK-467 treatment. Mean plasma insulin appeared to rise acutely at the start of exercise and subsequently dropped as exercise progressed. MK-467 produced a significant dose-related enhancement of the initial insulin response (peak levels during exercise: $111 \%$ of baseline on placebo, $155 \%$ on high dose MK-467). Similarly, MK-467 significantly enhanced the increase in FFA associated with exercise in a dose related manner (peak levels: $200 \%$ on placebo, $300 \%$ on high dose MK-467). This study shows that a peripherally selective $\alpha_{2}$-adrenoceptor antagonist significantly increases both resting and exercising NA, with no effect on $A$, suggesting blockade of $\alpha_{2}$-mediated feedback inhibition of NA release from sympathetic terminals. As measured by the increase in FFAs, enhancement of lipolysis also occurred. The increased exercise insulin response could well be attributed to the combination of $\alpha_{2}$-adrenoceptor blockade allowing unopposed insulin secretion. In summary we conclude that MK-467 treatment produced dose related increases in both resting and exercise NA, without influencing A levels, and an enhancement of the insulin and lipolytic response to exercise.

Table 1 Plasma noradrenaline levels $\left(\right.$ nmol $1^{-1}$, mean \pm s.e. mean)

\begin{tabular}{lcccc}
\hline & Pre-infusion & Start exercise & 6 min exercise & 10 min exercise \\
\hline $\mathrm{P}$ & $1.25 \pm 0.16$ & $1.92 \pm 0.22$ & $2.73 \pm 0.35$ & $5.33 \pm 1.49$ \\
$\mathrm{~L}$ & $1.46 \pm 0.11$ & $2.61 \pm 0.36^{*}$ & $3.47 \pm 0.63^{*}$ & $6.30 \pm 1.31$ \\
$\mathrm{H}$ & $1.17 \pm 0.14$ & $3.01 \pm 0.59^{*}$ & $4.15 \pm 0.56^{* *}$ & $6.59 \pm 1.51$ \\
$\mathrm{VO}_{2} \dagger$ & & 0.29 & 1.04 & 1.81 \\
\hline
\end{tabular}

$\dagger$ Mean oxygen consumption $\left(1 \mathrm{~min}^{-1}\right),{ }^{*} P<0.05$, ** $P<0.01$ vs placebo (P)

\section{A non-invasive approach to $\mathbf{P 6}$ anti-emesis in cancer chemotherapy}

J. YANG \& J. W. DUNDEE*

Northern Ireland Radiotherapy Centre, Belvoir Park Hospital, Belfast
While we have demonstrated conclusively that acupuncture (ACP) at P6 point is a useful adjuvant to standard antiemetics (Dundee et al., 1989a) it is invasive and one would like to develop a non-invasive approach (Dundee et al., 1989b). Although, in the perioperative 
situation transcutaneous electrical (TC) stimulation of P6 was not as effective an antiemetic as ACP (Dundee et al., 1989c) it warranted study in the more serious situation of cancer chemotherapy.

Patients with a history of sickness following previous chemotherapy had TC stimulation; $10-20 \mathrm{~Hz}$ DC, of P6 for 5 min via a conductive stud, increasing the current until 'chi' occurred. This was applied before chemotherapy and standard antiemetics were continued. Patients evaluated their benefit on a scale rating $A$ (complete relief) to $\mathrm{D}$ (no benefit). In 27 patients it was possible to compare both ACP and TC, but in others the findings in two consecutive series are reported.

Although TC stimulation was not as effective an adjuvant to standard antiemetics as $\mathrm{ACP}$, it gave considerable benefit in $72 \%$ applications. It is worthy of further study.

Table 1 Comparison of benefit when P6 ACP point was stimulated by needles (ACP) or by transcutaneous electrical stimulation (TC).

\begin{tabular}{|c|c|c|c|c|c|}
\hline & \multicolumn{2}{|c|}{ Crossover study } & \multicolumn{2}{|c|}{ Consecutive studies } \\
\hline & & $A C P$ & $T C$ & $A C P$ & $T C$ \\
\hline$n$ & & 27 & 27 & 132 & 202 \\
\hline \multirow[t]{3}{*}{ Benefit } & A & 23 & 11 & 96 & 93 \\
\hline & B & 4 & 7 & 29 & 66 \\
\hline & $\mathrm{C} / \mathrm{D}$ & 0 & 9 & 7 & 43 \\
\hline \multirow{2}{*}{\multicolumn{2}{|c|}{$\begin{array}{l}\chi^{2} \\
P=\end{array}$}} & \multicolumn{2}{|c|}{23.38} & \multicolumn{2}{|c|}{26.89} \\
\hline & & \multicolumn{2}{|c|}{0.0009} & \multicolumn{2}{|c|}{0.0001} \\
\hline
\end{tabular}

Dundee, J. W. et al. (1989a) J. Roy. Soc. Med., 82, 268-271.

Dundee, J. W. et al. (1989b) Br. J. clin. Pharmac., 28, 231P.
Dundee, J. W. et al. (1989c). Anesthesiology, 71, A130.
Effects of clonidine and yohimbine on the pupillary light reflex in healthy volunteers

\author{
M. J. MORLEY*, C. M. BRADSHAW \& E. \\ SZABADI \\ Department of Psychiatry, University of \\ Manchester, Stopford Building, Oxford Road, \\ Manchester M13 9PT
}

The miotic response evoked by brief light stimuli is mediated mainly by parasympathetic effector fibres, and the latency and amplitude of this response have been used as indices of parasympathetic functioning (see Lanting $e t$ al., 1988). The recovery phase of the response is believed to have a sympathetic component, since adrenergic neurone blocking drugs can delay the recovery of the baseline pupil diameter following light stimulation (Lowenstein \& Loewenfeld, 1962). We report here the effects of the $\alpha_{2}$-adrenoceptor agonist clonidine and the $\alpha_{2}$-adrenoceptor antagonist yohimbine, which are believed to suppress and enhance sympathetic outflow, respectively (Charney $e t$ al., 1983), on the light reflex.

Eight healthy male volunteers (18-30 years) participated in four sessions at 7-day intervals. In each session subjects ingested capsules containing one of the following: clonidine $\mathrm{HCl}$ $(200 \mu \mathrm{g})$, yohimbine $\mathrm{HCl}(22 \mathrm{mg})$, clonidine $\mathrm{HCl}(200 \mu \mathrm{g})+$ yohimbine $\mathrm{HCl}(22 \mathrm{mg})$, placebo, according to a balanced double-blind design. Two-and-a-half hours after ingestion, the subjects were acclimatized to red light $(30 \mathrm{~min})$; then resting pupil diameter and pupillary responses to 12 light stimuli $(0.2 \mathrm{~s}$, intensity range $0.09-180 \mathrm{mcd}$, peak wavelength $565 \mathrm{~nm}$ ), were measured using an infrared television pupillometer. For each response, latency to onset, amplitude, and time from the peak of the response to $75 \%$ recovery of the baseline pupil diameter were measured. Each measure was analyzed by two-factor analysis of variance (treatment, light intensity) with repeated measures, followed, in the case of a significant overall main effect of treatment, by individual 
comparisons between treatments using Dunnett's test (significance criterion, $P<0.05$ ).

Mean ( $\mathrm{mm} \pm$ s.e. mean) resting pupil diameter following yohimbine $(7.5 \pm 0.2)$ was significantly greater than following placebo $(7.1 \pm 0.2)$; the other treatments had no significant effect. Latency was inversely $(r=-0.94)$, and amplitude $(r=+0.99)$ and $75 \%$ recovery time $(r=$ $+0.95)$ directly related to log light intensity. The treatments had no significant effect on latency and amplitude. Clonidine significantly increased the $75 \%$ recovery times compared with placebo, whereas yohimbine had no significant effect; the $75 \%$ recovery times

Charney, D. S. et al. (1983). Life Sci., 33, 19.

Lanting, P. et al. (1988). J. Neurol., 235, 245.

Lowenstein, O. \& Loewenfeld, I. E. (1962). In The following clonidine + yohimbine were significantly shorter than following clonidine alone.

The data are consistent with the suggestion that clonidine suppresses the sympathetic influence on the iris dilator muscle which normally contributes to the termination of the light reflex. Yohimbine, while having no significant effect on its own, attenuated the effect of clonidine on the $75 \%$ recovery time, suggesting that $\alpha_{2}$-adrenoceptors may be involved in this effect.

This work was supported by the North Western Regional Health Authority.

Eye, ed. Davson, H., pp 231-267. New York: Academic Press.

\section{A comparison of the effects of chlorpromazine and temazepam on saccadic eye movements and psychomotor performance}

\section{J. KING*, P. BELL, S. J. BEST \& M. MANNION}

Department of Therapeutics and Pharmacology, The Queen's University of Belfast, 97 Lisburn Road, Belfast BT9 7BL, Northern Ireland

Rapid conjugate movements of the eye (saccades) are impaired by many but not all centrally acting drugs (Griffiths et al., 1984). The neurotransmitter mechanism(s) involved in this effect are unknown. We recently reported that, although haloperidol, a relatively selective dopamine antagonist, impaired performance on a continuous performance test (CPT) and digit symbol substitution (DSST), it had no effect on any saccadic eye movement measures (King \& Bell, 1990). In the present study the effect of chlorpromazine (CPZ), a non-selective neuroleptic with sedative properties was examined.

Single doses of CPZ (50 and $100 \mathrm{mg}$ ) were compared to temazepam (T) $(20 \mathrm{mg})$ and placebo (PI) in 12 healthy female volunteers by doubleblind balanced randomisation. Drug effects were measured using six saccadic parameters with the EOG/microcomputer-based system (CSGAAS) of Griffiths et al. (1984), a battery of conventional psychomotor tests and 16 visual analogue rating scales. Assessments were carried out at baseline, 0.5, 1, 2, 3 and $6 \mathrm{~h}$ and the data analysed by Friedman and Wilcoxon non-parametric statistics, comparing differences from baseline with placebo.

Compared with Pl, T and both doses of CPZ caused significant impairments in saccadic peak velocity (Table 1). CPZ also significantly reduced saccadic peak acceleration in a dosedependent manner at 2, 3 and $6 \mathrm{~h}$ and accuracy at $2 \mathrm{~h}(P<0.005)$. There was a similar pattern of effects on subjective alertness and critical flicker fusion threshold. Choice reaction time

Table 1 Saccadic peak velocity $\left({ }^{\circ} s^{-1}\right)$ medians (semi-interquartile range)

\begin{tabular}{lcccccc}
\hline & \multicolumn{5}{c}{ Time $(h)$} \\
& \multicolumn{1}{c}{0} & \multicolumn{1}{c}{0.5} & 1 & \multicolumn{1}{c}{2} & \multicolumn{1}{c}{3} & 6 \\
\hline Pl & $505.5(69.0)$ & $490.6(73.3)$ & $485.7(48.0)$ & $488.2(88.3)$ & $481.4(32.3)$ & $513.1(73.0)$ \\
T (20 mg) & $473.5(89.4)$ & $368.0(146.0)^{*}$ & $398.8(69.2)$ & $426.0(67.3)$ & $412.9(95.7)$ & $476.0(83.7)$ \\
CPZ (50 mg) & $504.1(59.9)$ & $466.3(80.7)$ & $492.2(53.1)$ & $474.3(140.9)$ & $427.3(116.1)$ & $455.8(69.2)^{* *}$ \\
CPZ (100 mg) & $493.3(57.9)$ & $467.9(91.8)$ & $444.3(80.1)$ & $372.7(106.0)^{* *}$ & $374.5(90.9)^{* *}$ & $380.4(70.5)^{* *}$ \\
\hline
\end{tabular}

Change from $0 \mathrm{~h}$ different from $\mathrm{Pl},{ }^{*} P<0.01 ;{ }^{* *} P<0.005$ 
was increased by $\mathrm{T}$ at $1 \mathrm{~h}(P<0.005)$ and $2 \mathrm{~h}$ $(P<0.01)$ but not by CPZ; DSST was impaired by $\mathrm{T}$ at $2 \mathrm{~h}$ and by $\mathrm{CPZ} 100 \mathrm{mg}$ at $6 \mathrm{~h}(P<$ 0.005 ); but no drug effects were detected by the CPT.

CPZ dose-dependently impaired saccadic eye

Griffiths, A. N. et al. (1984). Br. J. clin. Pharmac., 18, Suppl., 1, 73S. movement parameters with the peak effect being reached at $2 \mathrm{~h}$ and persisting for $6 \mathrm{~h}$ while $T$ had a transient effect at $0.5 \mathrm{~h}$. Saccadic peak velocity appears to be a sensitive but nonspecific measure of sedation.

King, D. J. \& Bell, P. (1990). Br. J. clin. Pharmac., 29, 590P.

\section{Relationships between plasma concentration of temazepam and effects of saccadic peak velocity in individual subjects}

\author{
A. L. van STEVENINCK*, S. VERVER, J. M. \\ KROON, H. C. SCHOEMAKER, D. D. BREIMER \\ \& A. F. COHEN \\ Centre for Human Drug Research, P.O. Box 9600, \\ 2300 RC Leiden, The Netherlands
}

Peak velocity of horizontal saccadic eye movements (PV) is known to be a sensitive measure of the effect of benzodiazepines on the central nervous system. Negative correlations between plasma concentrations of diazepam, temazepam and nitrazepam and effects on PV have been reported using combined data from groups of volunteers (Bittencourt et al., 1981). No studies have yet been published confirming this relationship in individual subjects. This study aimed at describing relationships between plasma concentrations of temazepam (T) and effects on PV in individual subjects.

The study was a double-blind, randomised, placebo controlled cross-over trial in eight healthy volunteers $(4 \mathrm{M}, 4 \mathrm{~F})$ with a washout period of 1 week. Active treatment. consisted of single oral doses of $20 \mathrm{mg} \mathrm{T}$ in soft gelatin capsules $\quad$ (Normison ${ }^{\circledR}$ ). Subjects received medications at $08.30 \mathrm{~h}$ after an overnight fast. Plasma samples $(n=19)$ and measures of PV $(n=43)$ were taken between 0 and $33.5 \mathrm{~h}$ after intake of medications. Concentrations of $\mathrm{T}$ were determined by h.p.l.c. (Ho et al., 1983). Eye movements were measured by electrooculography and subsequently analyzed on a microcomputer (van Steveninck et al., 1989).

Average pharmacokinetic parameters ( \pm s.d.) were; $t_{\max }: 37 \pm 10 \mathrm{~min}, C_{\max }: 623 \pm$ $218 \mathrm{ng} \mathrm{ml}^{-1}, t_{1 / 2,2}: 618 \pm 175 \mathrm{~min}$. A second peak in concentrations of $\mathrm{T}$ occurred in seven out of eight subjects at approximately $120 \mathrm{~min}$. PV was decreased significantly $(P<0.05)$ until 300 min after treatment with T. Plasma concentrations at $300 \mathrm{~min}$ averaged $178 \pm 135 \mathrm{ng}$ $\mathrm{ml}^{-1}$. Individual linear regressions between concentrations of $\mathrm{T}$ derived from linear interpolations of concentration-time data and PV are shown in Table 1 . No clear indication of hysteresis was found on inspection of concentration effect plots.

A linear relationship of concentrations of $T$ and effects on PV can be demonstrated in individual subjects. The average minimal effective concentration of $\mathrm{T}$ appears to be 180 $\mathrm{ng} \mathrm{ml}^{-1}$, as judged from concentrations of $\mathrm{T}$ at $300 \mathrm{~min}$.

Table 1 Linear regression of $\mathrm{PV}\left({ }^{\circ} \mathrm{s}^{-1}\right)$ and concentrations of temazepam $\left(\mathrm{ng} \mathrm{ml} \mathrm{m}^{-1}\right)$

\begin{tabular}{llrrrrrrrrr}
\hline Subject & & 1 & 2 & 3 & 4 & 5 & 6 & 7 & 8 & Average \\
\hline & & & & & & & & & & \\
Intercept & $\left({ }^{\circ} \mathrm{s}^{-1}\right)$ & 392 & 469 & 429 & 390 & 552 & 362 & 528 & 510 & 454 \\
Slope & $\left({ }^{\circ} \mathrm{s}^{-1} \mathrm{ml} \mathrm{ng}^{-1}\right)$ & -0.18 & -0.13 & -0.11 & -0.32 & -0.16 & -0.17 & -0.46 & -0.11 & -0.21 \\
$r$ value & & -0.68 & -0.65 & -0.86 & -0.92 & -0.92 & -0.92 & -0.90 & -0.71 & -0.82 \\
\hline
\end{tabular}

Bittencourt, P. R. M. et al. (1981). Br. J. clin. Pharmac., 12, 523.

Ho, P. C. et al. (1983). Ther. Drug. Monit., 5, 303. van Steveninck, A. L. et al. (1989), Br. J. clin. Pharmac., 27, 712 . 


\section{Fantasies during benzodiazepine sedation} in women

\section{J. W. DUNDEE*}

Department of Anaesthetics, The Queen's University of Belfast, Whitla Medical Building, 97 Lisburn Road, Belfast BT9 7BL

Anecdotal stories of patients experiencing sexual fantasies during i.v. benzodiazepine sedation have proven to be more serious than originally thought. Several dentists have been deprived of the right to practise because of claims of sexual assault when the patient was under the influence of diazepam or midazolam. As the result of reporting an early case (Dundee, 1986), together with radio and press publicity the author has got details of 41 such incidents.

In 17 out of 25 verified incidents, despite the logical description of events which the patient reported to have occurred, nothing improper had happened. Others were present throughout the sedation (15) or the event which the patient described was physically impossible (2). Because of their reality it was often difficult to persuade patients of their error. The events during the slow induction of anaesthesia were quite different. Although of a sexual nature they were not unpleasant and no one complained of them.

When details of the events, both actual happenings and those reported to have occurred were sufficiently clear, it was possible to see a clear relation between something during the procedure and the complaints in 7 out of 13 patients. The commonest one was 'oral sex' during dentistry or endoscopy (4), fondling the breasts (2) and a 'wandering hand' (2).

The cause of these fantasies is not known, but in view of the legal implications, an intelligent third person, preferably of the same sex as the patient should always be present during sedation.

\section{Table 1 Summary of incidents}

41 possible 'fantasies' or hallucinations

33 in women

27 during sedation (dentistry 16: oral endoscopy 7 : others 4)

6 during slow induction of anaesthesia

27 had some sexual element (20 unpleasant)

25 verified reports of sexual fantasies

17 did not happen

9/13 proven fantasies could be related to something that happened.

Dundee, J. W. (1986). SAAD Digest, 6, 72.

\section{A comparison of a short-life marker, a long half-life indicator and a slow release 'therapeutic' drug for detecting incomplete compliance}

\author{
E. HARDY, S. KUMAR, S. PEAKER, \\ M. FEELY \& T. PULLAR* \\ Clinical Pharmacology Unit, University Department \\ of Medicine, The General Infirmary, \\ Leeds LS1 3EX
}

It has been stated that compliance with drug treatment may be assessed using detection of a short half-life marker (Ellard et al., 1980), or measurement of plasma concentration of a long half-life indicator (Feely et al., 1987) or of the therapeutic drug.

To compare these methods we administered oral phenobarbitone $2 \mathrm{mg}$, isoniazid $6 \mathrm{mg}$ and sustained release metoprolol ('Metoros') $95 \mathrm{mg}$ or $190 \mathrm{mg}$ to seven healthy volunteers (age 2843 years) regularly for 28 days but omitted every 3rd day's dose. Plasma taken immediately before the dose 'was due' and 2 and $6 \mathrm{~h}$ afterwards on days $1,8,15,22$ and 28 was assayed for phenobarbitone (h.p.l.c.) and metoprolol (g.c.) while urine taken at the same time was tested for the presence of isoniazid and metabolites using a colorimetric method. At the end of the study tablets were taken daily for 4 days to allow volunteers to reach steady-state for metoprolol and isoniazid. All had received phenobarbitone daily for 28 days to achieve steady-state on a previous occasion.

On day 28 of simulated poor compliance (tablets taken days 27 and 28) phenobarbitone levels ranged from 58-91\% (median 70\%; IQ range $66-76 \%$ ) of steady-state levels whereas metoprolol levels ranged from $0-214 \%$ (median $82 \%$; IQ range $37-100 \%$ ) of steady-state levels. Overall sensitivity and specificity of isoniazid for detecting ingestion within the previous $24 \mathrm{~h}$ was $83 \%$ and $94 \%$ respectively. However, isoniazid gave no indication of longer term 
ingestion, e.g. all volunteers were positive after their first dose but on 13 and 14 occasions were negative only $2 \mathrm{~h}$ after a missed dose.

Thus, low-dose phenobarbitone was the best indicator of compliance over the previous 4

Ellard, G. A. et al. (1980). Br. J. clin. Phamac., 10, 369. weeks with metoprolol and isoniazid unhelpful in this situation. Isoniazid was very specific for detecting recent ingestion during the past $24 \mathrm{~h}$ but failed to detect such ingestion in $17 \%$ of instances.

Feely, M. et al. (1987). Br. J. clin. Pharmac., 24, 77.
The 4-hydroxylation of (s)-mephenytoin in Nigerians: a population study

\section{A. O. IYUN, G. T. TUCKER, H. F. WOODS \& M. S. LENNARD* \\ University Department of Medicine and Pharmacology, Royal Hallamshire Hospital, Sheffield S10 2JF and Department of Medicine, University College Hospital, Ibadan, Nigeria}

The genetic polymorphism of (S)-mephenytoin (S-M) 4-hydroxylation shows marked ethnic differences. Thus, 3-5\% of Caucasians are poor metabolisers, whereas the prevalence is about $20 \%$ in Orientals (Wilkinson et al., 1989). We have investigated the role of genetic polymorphism in the 4-hydroxylation of S-M in a Negroid population of 92 Nigerians.

Each subject was given $100 \mathrm{mg}$ racemic $M$ p.o. and all urine was collected during the following $8 \mathrm{~h}$. 4-Hydroxymephenytoin (4HM) was measured by h.p.l.c. after acid hydrolysis of its conjugates. The ratio of S-M to R-M was determined using chiral g.l.c.

Members of the population excreted between 0.07 and $33.0 \%$ (median $13.7 \%$ ) of the dose as 4-HM. The distribution of the $\log _{10} \mathrm{M}$ hydroxylation index (MHI = dose of $\mathrm{S}-\mathrm{M} / \%$ recovery of $4 \mathrm{HM})$ appeared to be bimodal. Four $(4.3 \%)$

Wilkinson, G. R. et al. (1982). Pharmac. Ther., 43, 53.

\section{Prevalence of cough in patients taking enalapril: controlled study vs nifedipine}

\author{
W. W. YEO*, G. FOSTER \& L. E. RAMSAY \\ University Department of Medicine and \\ Pharmacology, Royal Hallamshire Hospital, \\ Sheffield S10 2JF
}

Persistent cough is a recognised side effect of ACE inhibitors with an incidence of approximately $15 \%$ in uncontrolled surveys (Just, 1989; Yeo \& Ramsay, 1989). Few studies examining of the subjects had values of MHI that were much higher than the remainder of the population and excreted negligible quantities $(<1.5 \%)$ of the dose as $4 \mathrm{HM}$. However, the urine collection in one of these subjects may have been incomplete. The S/R-ratio ranged from 0.007 to 1.11 (median 0.22). Although this ratio correlated weakly with the MHI $(r=0.40$, $P<0.001$ ), its distribution did not appear to display bimodality and the values for those subjects with negligible $4 \mathrm{HM}$ excretion were not significantly different from those of the remainder of the population $(P>0.05)$. In addition, the presence of two groups was not evident on inspection of the M/4-HM ratio data.

These data provide some evidence that the 4-hydroxylation of mephenytoin is polymorphic in Nigerians. In contrast to findings in Caucasians, the S/R-M ratio did not discriminate between apparent extensive and poor metabolisers of mephenytoin in Nigerians. This observation emphasises the difficulty of extrapolating results from one ethnic group to another. Furthermore, detection of polymorphism may be confounded by the choice of metabolic index, the limitations in assay sensitivity and the lack of objective proof of bimodality in frequency distributions. cough have included controls, and none has estimated the prevalence of cough after longterm treatment in a controlled manner.

We have examined the prevalence of ACE inhibitor-induced cough in hypertensive patients treated with enalapril for 1-4 years, in comparison with matched patients treated with nifedipine. We identified all patients attending the Sheffield hypertension clinic during 3 years from January 1986-December 1988. Each enalapril-treated patient was matched for age and sex with a patient who started nifedipine 
during the same year. The prevalence, severity, and character of cough were assessed by questionnaire in 130 matched pairs of patients (excluding six pairs where a patient had died). The questionnaire was designed to give equal weighting to headache and persistent cough, and also asked about smoking, therapy and other symptoms.

Of 260 questionnaires sent $212(82 \%)$ were returned. Forty-four patients were no longer on the index drug and 18 did not complete the questionnaire, had moved away or had died. The analysis included 81 patients $(62 \%)$ on enalapril and 69 (53\%) on nifedipine. The difference was accounted for by the increased number of patients initially on nifedipine who were no longer on the index drug ( $22 \%$ vs $12 \%)$. The two groups were well-matched for age, sex, duration of therapy, antihypertensive therapy, smoking and orthopnoea. Reported chronic respiratory disease was more common in the enalapril group

Just, P. M. (1989). Pharmacotherapy, 9, 82.
(14 vs $3 ; \chi^{2}=5.8 P<0.05$ ). Persistent cough was more frequent in the enalapril group but common in both (20 vs 12; $P=\mathrm{NS}$ ). However the prevalence of new cough after starting therapy was significantly higher in the enalapril group for all patients $\left(14 v s 1 ; \chi^{2}=8.7 P<\right.$ $0.01)$ and for women $\left(10 / 43\right.$ vs $0 / 39 ; \chi^{2}=8.3$ $P<0.01)$. The higher prevalence of new cough persisted even when those reporting respiratory disease were excluded from the analyses (all patients: $10 / 67$ vs $1 / 66 ; \chi^{2}=6.2 P<0.025$; women $6 / 36$ vs $0 / 36 ; \chi^{2}=4.5 P<0.05$ ).

This survey confirms that the prevalence of new persistent cough with enalapril treatment is $15.9 \%(95 \%$ CI $7.2-24.6 \%)$ even after $1-4$ years, and this does not include patients who had stopped enalapril because of cough. The prevalence is higher in women $23.3 \%$ (95\% CI $10.7-35.9 \%)$ than in men $7.2 \%(95 \%$ CI 4.4 $18.8 \%)$.

Yeo, W. W. \& Ramsay, L. E. (1989). Br. J. clin. Pharmac., 28, 245P.

\section{Sustained-release verapamil and nifedipine in exercise-induced angina pectoris}

\section{R. A. FOALE* \& M. J. VANDENBURG ${ }^{1}$}

St Mary's Hospital, London, W2 1NY and ${ }^{1}$ MCRC, 1 Mildmay Road, Romford, Essex RM7 7DA.

A randomised, double-blind, two period crossover study of oral sustained-release verapamil $360 \mathrm{mg}$ once daily (SR-verapamil) and oral nifedipine $20 \mathrm{mg}$ three times daily has been undertaken in 19 patients (17 men, two women, mean age 62 years) with chronic stable angina pectoris. All patients had positive ischaemic responses to exercise testing after a 1 week placebo washout period prior to the trial. Signifcantly greater improvement from baseline was seen with 4 weeks treatment with SR-verapamil than with the same period of treatment with nifedipine.

Mean (s.d.) exercise duration was 380 (108) s with SR-verapamil and 343 (130) s with nifedipine $(P=0.018$, generalised linear modelling); mean time to onset of angina was 326 (79) s with SR-verapamil and 239 (57) s with nifedipine $(P=0.004)$; median (inter-quartile range) time to $1 \mathrm{~mm}$ ST-depression was 252 (192-333) s with SR-verapamil and 182 (141-367) s with nifedipine $(P=0.002$, Koch's method); mean ST-depression at maximum exercise was 1.65 (0.56) $\mathrm{mm}$ with SR-verapamil and $2.17(0.98)$ $\mathrm{mm}$ with nifedipine $(P=0.016)$. Although ambulatory ECG recordings revealed appreciable numbers of spontaneous ischaemic episodes in only six patients, there was a trend in favour of SR-verapamil (median ST-time integral $0.0(0.0-1.06)$ units with SR-verapamil, 1.15 (0-3.94) units with nifedipine, $P$ NS, Koch's method). The median number of glyceryl trinitrate tablets consumed was significantly lower $(P=0.026)$ with SR-verapamil $(0.21(0-0.5)$ per day) than with nifedipine $(0.13(0-0.77)$ per day), although there was no significant difference between the frequency of angina attacks recorded. Possible adverse events were reported by two patients with SR-verapamil (constipation in both cases) and nine patients with nifedipine (oedema, headaches, dizziness, constipation, dyspepsia and flushing).

Once daily sustained release verapamil $360 \mathrm{mg}$ has greater anti-anginal efficacy than nifedipine $20 \mathrm{mg}$ three times daily and also appears to be better-tolerated. 


\section{Paradoxical actions of cromakalim on systolic and diastolic function in coronary disease}

\section{S. GUY*, S. P. VERMA \& B. SILKE}

Department of Therapeutics and Pharmacology, The Queen's University of Belfast, 97 Lisburn Road, Belfast BT9 7BL, Northern Ireland

The haemodynamic dose-response effects of cromakalim were evaluated in 12 patients with angiographically documented coronary artery disease. Patients underwent a 4 min period of supine bicycle exercise at a pre-determined level, with haemodynamic measurements made at 1, 2, 3 and $4 \mathrm{~min}$. Following a $20 \mathrm{~min}$ rest there was a control saline period with reproducible baseline parameters. The haemodynamic and radionuclide effects of four doses of the drug $\left(1,2,4\right.$ and $8 \mu \mathrm{g} \mathrm{kg}^{-1}$ given as a 10 min i.v. infusion) were measured in the 5-10 min following infusion. The exercise effects of the cumulative $15 \mu \mathrm{g} \mathrm{kg}^{-1}$ dosage on haemodynamic and radionuclide parameters were determined from a comparison of control (drug free) and post-drug periods of supine bicycle exercise, at the same individually titrated workload.
Cromakalim at rest did not alter mean arterial blood pressure but the systemic vascular resistance index fell at the two highest dosages. There were dose-related increases in heart rate, cardiac and stroke volume indices. The left ventricular ejection fraction significantly increased with a reduction in cardiac volumes. However systolic function deteriorated as evidenced by an increased ejection time $(+44$ ms: $P<0.05)$ and a dose-related reduction in peak ejection rate. An improved diastolic function was suggested from the increased filling rate $\left(+56 \mathrm{~cm} \mathrm{~s}^{-1}\right)$ and the dose-related reduction in filling time. During supine bicycle exercise, the heart rate, cardiac and stroke volume indices increased; left ventricular filling pressures and systemic vascular resistance index fell. The peak filling rate improved $(+61 \mathrm{~cm}$ $\left.\mathrm{s}^{-1}\right)$.

These effects suggested that an augmented pumping action at an unchanged left ventricular afterload resulted in a dose-related deterioration in systolic function at rest; however diastolic function was significantly augmented. The implications of such findings for the ischaemic ventricle warrant further study.

Table 1 Dose-response effects on cromakalim in coronary disease

\begin{tabular}{|c|c|c|c|c|c|c|}
\hline & \multicolumn{6}{|c|}{ Cromakalim ( $\mu g \mathrm{~kg}^{-1}$ ) } \\
\hline & Control & 1 & 2 & 4 & 8 & Exercise \\
\hline MAP (mm Hg) & $101(5)$ & $101(4)$ & $101(4)$ & $100(4)$ & $97(4)$ & -1 \\
\hline HR (beats $\min ^{-1}$ ) & $67(4)$ & $69(4)$ & $69(4)$ & $71(4)$ & $73(4)^{* *}$ & $+3^{*}$ \\
\hline CI $\left(1 \min ^{-1} \mathrm{~m}^{-2}\right)$ & $3.3(0.2)$ & $3.3(0.2)$ & $3.4(0.2)$ & $3.6(0.2)^{* *}$ & $3.9(0.2)^{* *}$ & $+0.6^{* *}$ \\
\hline PWP (mm Hg) & $12.7(0.6)$ & $12.4(0.1)$ & $12.8(1.2)$ & $12.3(1)$ & $11.3(1.1)$ & $-3^{*}$ \\
\hline EF (\%) & $35(2)$ & $33(2)$ & $36(2)$ & $40(2)^{* *}$ & $40(2)^{* *}$ & +4 \\
\hline $\operatorname{PER}\left(\mathrm{cm} \mathrm{s}^{-1}\right)$ & $392(20)$ & $375(20)$ & 367 (17)* & 370 (23)* & $352(19)^{* *}$ & +11 \\
\hline FT (ms) & $498(30)$ & $466(28)^{*}$ & $462(24)^{*}$ & $446(27)^{* *}$ & $419(22)^{* *}$ & -20 \\
\hline
\end{tabular}

Change from control: two way ANOVA, ${ }^{*} P<0.05 ;{ }^{* *} P<0.01$

\section{Clinical studies with cromakalim in normotensive and hypertensive subjects}

R. DONNELLY*, H. L. ELLIOTT, P. A. MEREDITH \& J. L. REID

University Department of Medicine and Therapeutics, Stobhill Hospital, Glasgow G21 3UW

Pharmacological studies with the smooth muscle relaxant drug cromakalim, both in vitro and in vivo, have suggested that it may be useful for the treatment of hypertension. As yet there is only limited information about the vasodilator activity of cromakalim in man. We report two studies with cromakalim in normotensive and hypertensive subjects.

Study 1: Eight healthy males received single $(1 \mathrm{mg})$ and multiple doses of cromakalim $(1 \mathrm{mg}$ daily for 7 days) and placebo in a randomised, double-blind crossover study. Each subject 
attended four $8 \mathrm{~h}$ study days to evaluate the effects of cromakalim on supine and erect blood pressure (BP) and heart rate (HR) and venous blood samples were collected for plasma noradrenaline, renin activity and aldosterone. Pressor responses to intravenous infusions of noradrenaline (NA) and angiotensin II (AII) were assessed at 3-4 $\mathrm{h}$ and the $\mathrm{PD}_{15}$ values derived (i.e. the doses of agonist required to increase mean BP by $15 \mathrm{~mm} \mathrm{Hg}$ ).

Study 2: Ten hypertensive patients (4M, 45-69 years) with blood pressures $>150 / 90$ $\mathrm{mm} \mathrm{Hg}$ after 3 months treatment with atenolol $50 \mathrm{mg}$ received additional treatment with placebo for 3 weeks followed by cromakalim $1 \mathrm{mg}$ daily for 4 weeks. The average entry BP \pm s.d. was $178 / 102 \pm 9 / 6 \mathrm{~mm} \mathrm{Hg}$ supine. Atenolol was continued unchanged throughout and each patient attended three $8 \mathrm{~h}$ study days to evaluate the effects of additional placebo, first dose cromakalim and after cromakalim for 4 weeks. During each study day BP and HR were recorded and blood samples collected for the measurements of plasma atenolol concentrations. Apparent hepatic blood flow, glomerular filtration rate (GFR) and effective renal plasma flow (ERPF) were determined at $3 \mathrm{~h}$ by the clearances of ICG, $I^{125}$-hippuran and chromium $^{51}$ EDTA, respectively.

Cromakalim was generally well tolerated in both studies. In the normotensives cromakalim had no effect on BP but was associated with significant increases in HR: for example, from a baseline of $74 \pm 6$ to $92 \pm 6$ beats $\min ^{-1} 4 \mathrm{~h}$ after the 1st dose, compared with $77 \pm 9$ to 79 \pm 1 beats $\min ^{-1}$ following placebo. There was no effect on pressor responsiveness to NA and AII: e.g. mean $\mathrm{PD}_{15}$ values for AII were 20.3 $\pm 5.6 \mathrm{ng} \mathrm{kg}^{-1} \mathrm{~min}^{-1}$ after 7 days cromakalim compared with $23.5 \pm 14.6$ after placebo. In the hypertensives the addition of cromakalim to atenolol was associated with significant but modest reductions in BP only between $0.5-3 \mathrm{~h}$ after drug administration: for example, from a baseline of $158 / 93 \pm 19 / 9$ to $130 / 74 \pm 19 / 12$ $\mathrm{mm} \mathrm{Hg}$ (supine) at $2 \mathrm{~h}$ after the first dose, compared with changes from 171/100 $\pm 18 / 10$ to $151 / 88 \pm 20 / 13 \mathrm{~mm} \mathrm{Hg}$ with placebo. Cromakalim had no significant effect on hepatic and renal blood flow, or on the steady state pharmacokinetics of atenolol.

In summary, single and multiple doses of cromakalim $1 \mathrm{mg}$ were well tolerated but associated with only modest vasodilator antihypertensive activity. There was no evidence that cromakalim altered renal or hepatic blood flow. These results suggest that it may be necessary to use higher doses of cromakalim, perhaps several times daily, to achieve a clinically useful antihypertensive effect.

\section{Does the sympathetic nervous system assist or oppose the natriuretic effect of atrial natriuretic factor in man?}

\section{C. LANG, A. M. CHOY, L. A. GIBB \& A. D. STRUTHERS}

Department of Clinical Pharmacology, Ninewells Hospital and Medical School, Dundee DD1 9SY, Scotland

There has been much interest in the intra-renal mechanisms of action of atrial natriuretic factor (ANF). Most studies have investigated the glomerular and tubular sites of action of ANF but there has been relatively little investigation of possible interactions between ANF and other antidiuretic and antinatriuretic neuroendocrine determinants of renal sodium and water excretion in man. One such influence on renal function is the sympathetic nervous system (SNS). In man there is evidence for a preferential interaction between ANF and noradrenergic blood pressure control mechanisms
(Uehlinger et al., 1986). There is also increasing evidence of a generalised interaction between ANF and the SNS (Holtz et al., 1987). In particular, the renal SNS may modulate the effects of ANF (Morgan et al., 1986). We have now studied the effects of a non-depressor dose of prazosin (PRZ), an $\alpha_{1}$-adrenoceptor antagonist on the renal effects of ANF in man.

Eight male volunteers aged 19 to 22 years were studied on four occasions. In addition to a conventional overhydration protocol, lithium clearance $\left(\mathrm{CL}_{\mathrm{Li}}\right)$ procedure was employed to assess proximal tubular $\mathrm{Na}^{+}$reabsorption. After an equilibration period of $1.5 \mathrm{~h}$, the following treatment combinations were administered in single-blind randomised fashion: PRZ $0.25 \mathrm{mg}+5 \%$ D-glucose (P), PRZ $0.25 \mathrm{mg}+$ ANF 5 pmol kg-1 $\min ^{-1}, \mathrm{P}+$ ANF 5 pmol $\mathrm{kg}^{-1} \min ^{-1}, \mathrm{P}+\mathrm{P}$ : Values are shown as mean \pm s.e. mean for baseline and maximal responses.

The absolute $\mathrm{Na}^{+}$excretion ( $\mathrm{UNa}+\mathrm{V}$ ) $\left(\mu \mathrm{mol} \min ^{-1}\right.$ ) on all 4 study days was: $\mathrm{P}+\mathrm{P}$ : $161 \pm 18,138 \pm 15 ;$ PRZ + P: $167 \pm 14,126$ 
\pm 9; P + ANF: $171 \pm 10,323 \pm 108 ; \mathrm{PRZ}+$ ANF: $21,226 \pm 29(P<0.01)$.

The mean arterial pressure $(\mathrm{mm} \mathrm{Hg})$ on all 4 study days was: $\mathrm{P}+\mathrm{P}: 90 \pm 2,92 \pm 2$; PRZ + P: $93 \pm 1,94 \pm 3, \mathrm{P}+$ ANF: $91 \pm 3,89 \pm$ 6; PRZ + ANF: $90 \pm 2,90 \pm 2 \mathrm{CL}_{\mathrm{Li}}(\mathrm{ml}$ $\left.\min ^{-1}\right): \mathrm{P}+\mathrm{P}: 28 \pm 2,26 \pm 2 \mathrm{p} \mathrm{PRZ}+\mathrm{P}: 30$ $\pm 1,25 \pm 1 ; \mathrm{P}+$ ANF: $26 \pm 2,32 \pm 2$; PRZ + ANF: $26 \pm 2,29 \pm 2(P<0.05)$.

In conclusion, we have shown that prazosin

Holtz, J. et al. (1987). Hypertension, 9, 350-354. Morgan, D. A. et al. (1986). Clin. Res., 34, 937A. markedly blunts the natriuretic effect of ANF. We have therefore shown that the SNS contributes positively to the natriuretic effect of ANF in normal man. Patients with CHF have elevated SNS activity and ANF levels. They were previously thought to oppose each other in terms of urinary sodium output but this study suggests that the SNS might help maintain some natriuretic effect for ANF.

Uehlinger, D. E. et al. (1986). J. clin. Endocrinol. Metab., 63, 669.

\section{A dose-ranging study to evaluate the $\beta$ - adrenoceptor selectivity of betaxolol}

\section{B. J. LIPWORTH*, N. A. IRVINE \& D. G. McDEVITT}

Department of Clinical Pharmacology, Ninewells Hospital and Medical School, Dundee, Scotland

Betaxolol is one of a group of so called cardioselective drugs which exhibit selective antagonism of $\beta_{1}$-adrenoceptors. We have previously shown that increasing doses of atenolol are associated with dose-dependent $\beta_{2}$-adrenoceptor blockade (Lipworth et al., $1989 a, b)$. The purpose of the present study was to perform a dose-ranging study with betaxolol to assess its relative antagonism of $\beta_{1}$-adrenoceptors (assessed by reduction of exercise heart rate $[E H R]$ ), and $\beta_{2}$-adrenoceptors (assessed by attenuation of isoprenaline-induced responses). Six normal subjects ( $25 \pm 2$ years) were given single oral doses of betaxolol $10 \mathrm{mg}$ (B10), $20 \mathrm{mg}$ (B20), $40 \mathrm{mg}$ (B40), $80 \mathrm{mg}$ (B80); propranolol $40 \mathrm{mg}(\mathrm{P} 40)$; or placebo (PL) in a single-blind randomised cross-over design. Dose-response curves were constructed $(3 \mathrm{~h}$ after drug ingestion) using serial incremental 8 min infusions of isoprenaline $\left(1-20 \mu \mathrm{g} \mathrm{min}^{-1}\right)$, followed by a standardised exercise step-test. Individual regression lines were used to calculate doses of isoprenaline required to increase finger tremor by $200 \%\left(\mathrm{IT}_{200}\right)$, heart rate by 25 beats $\min ^{-1}\left(\mathrm{IH}_{25}\right)$, calf blood flow by $0.5 \mathrm{ml}$ $\mathrm{dl}^{-1} \min ^{-1}\left(\mathrm{IC}_{0.5}\right)$, systolic blood pressure by $25 \mathrm{~mm} \mathrm{Hg}\left(\mathrm{IS}_{25}\right)$; and to decrease diastolic blood pressure by $10 \mathrm{~mm} \mathrm{Hg}\left(\mathrm{ID}_{10}\right)$. These indices were compared with placebo responses and expressed as dose-ratios. Comparisons were made by two-way ANOVA.

There were no significant changes in plasma drug concentrations taken over the duration of the study period. Mean \pm s.e. mean plasma levels were as follows ( $\mathrm{ng} \mathrm{ml}$ ) : $22.3 \pm 4.4$ (B10), $34.6 \pm 3.7$ (B20), $48.7 \pm 6.4$ (B40), 56.3 \pm 10.7 (B80), and $23.4 \pm 2.7$ (P40). Betaxolol produced dose-related reductions in EHR (beats $\mathrm{min}^{-1}$ ) up to a ceiling at B40, after which B80 showed a diminished effect (comparison with PL, $158 \pm 8$ beats $\left.\min ^{-1}\right)$ : B10 $(128 \pm 3$, $P<0.005)$, B20 (123 $\pm 2, P<0.005)$, B40 (116 $\pm 4, P<0.005)$, B80 (136 \pm 10, NS); P40 (135 $\pm 4, P<0.005)$. Propranolol produced significantly less reduction of EHR in comparison with $\mathrm{B} 10, \mathrm{~B} 20$ and $\mathrm{B} 40(P<0.001)$. Doseratios for $\mathrm{IT}_{200}$ showed significant attenuation by all doses of betaxolol, with a plateau in effect above the $20 \mathrm{mg}$ dose (comparison with PL): B10 $1.5 \pm 0.18(P<0.05)$, B20 $2.62 \pm$ $0.45(P<0.005)$, B40 $2.55 \pm 0.33(P<0.001)$, B80 $2.48 \pm 0.48(P<0.01):$ P40 $6.49 \pm 1.12$ $(P<0.001)$. Propranolol caused a greater degree of $\beta_{2}$-adrenoceptor blockade than all doses of betaxolol $(P<0.05)$. Dose-ratios for $\mathrm{IH}_{25}, \mathrm{IC}_{0.5}$ and $\mathrm{ID}_{10}$ showed similar attenuation of isoprenaline-induced responses, with a plateau in effect above B20, and significantly less $\beta_{2}$-adrenoceptor blockade in comparison with P40. Dose-ratios for IS $_{25} \quad\left(\beta_{1}\right.$ effect) showed a similar pattern to that of EHR: B10 $1.58 \pm 0.32$ (NS), B20 $2.48 \pm 0.38(P<0.01)$, B40 $2.74 \pm 0.46(P<0.005)$, B80 $2.04 \pm 0.75$ (NS), P40 $2.65 \pm 0.50(P<0.01)$. Thus, betaxolol exhibited partial loss of selective $\beta_{1}$-adrenoceptor antagonism at doses used in normal clinical practice $(10-40 \mathrm{mg})$, although $\beta_{2}$-adrenoceptor blockade was significantly less than that of propranolol. The $80 \mathrm{mg}$ dose was associated with diminished reduction of EHR, which would suggest partial agonist activity at $\beta_{1}$-adrenoceptors. Similarly, the 
plateau in $\beta_{2}$-adrenoceptor blockade at doses greater than $20 \mathrm{mg}$ might also be explained by

Lipworth, B. J. et al. (1989a). Br. J. clin. Pharmac., 28,95 . a partial $\beta_{2}$-adrenoceptor agonist effect at higher doses of betaxolol.

Lipworth, B. J. et al. (1989b). Eur. J. clin. Phamac., 37, 297.

\section{The effects of flosequinan on regional blood flow in normal man}

\section{R. A. SCOTT*, K. L. WOODS \& D. B. BARNETT Department of Pharmacology, University of Leicester, Leicester LE2 7LX}

Flosequinan $(\mathrm{F})$ is a novel arteriovenous dilator. In preliminary studies in normal volunteers the drug reduces blood pressure (BP) and forearm vascular resistance (FVR) (Cowley et al., 1984) while reducing BP and preserving renal blood flow in essential hypertension (Dupont et al., 1988). We have investigated the effects of two doses of $\mathrm{F}$ on limb, hepatic and renal blood flow in 14 healthy male volunteers aged 18-40 years.

On each of 3 study days with a washout period of 2 weeks $F 100 \mathrm{mg}, 200 \mathrm{mg}$ or matching placebo was administered orally in double-blind randomised fashion $1 \mathrm{~h}$ after a light breakfast. Subjects were rested semi-supine and heart rate (HR), BP, forearm blood flow (FBF) and venous capacitance (FVC) measured by volume plethysmography were recorded at baseline, at $30 \mathrm{~min}$ intervals for $2 \mathrm{~h}$ and at $4 \mathrm{~h}$ post-dose.
Apparent hepatic and renal blood flows (AHBF, ARBF) were estimated $2 \mathrm{~h}$ post dose by indocyanine green dye clearance and clearance of ${ }^{125}$-iodohippuran respectively. Regional vascular resistance was calculated by dividing mean $\mathrm{BP}$ by regional blood flow.

The mean (s.e. mean) weight of the volunteers was $76.2(2.5) \mathrm{kg}$. F significantly reduced diastolic BP $(P=0.0001)$ in a dose dependent fashion and increased HR $(P=0.05)$. FBF tended to increase after $F$ compared with placebo $(P=0.09), 200 \mathrm{mg}$ producing a maximal increase after $4 \mathrm{~h}(P=0.03)$ and FVR decreased in a similar fashion. FVC was unchanged.

AHBF tended to increase after F (Table 1). The effects on hepatic vascular resistance were similar. ARBF was unchanged but renal vascular resistance was significantly reduced. Three subjects failed to complete the study.

In normal man $F$ produces dose dependent BP reduction while preserving blood flow to limb, hepatic and renal vascular beds via reductions in regional vascular resistance. These effects require further evaluation in hypertension and congestive heart failure.

Table 1 Hepatic and renal blood flows and vascular resistance $2 \mathrm{~h}$ after dosing

\begin{tabular}{lccc}
\hline & \multicolumn{2}{c}{ Flosequinan } \\
& Placebo $(\mathrm{n}=11)$ & $100 \mathrm{mg}(\mathrm{n}=13)$ & $200 \mathrm{mg}(\mathrm{n}=12)$ \\
\hline Hepatic blood flow $\left(\mathrm{ml} \mathrm{min}^{-1} \mathrm{~m}^{-2}\right)$ & $426(38)$ & $448(31)$ & $456(31)^{*}$ \\
Hepatic vascular resistance $\left(\mathrm{units}^{*}\right)$ & $117.6(12.6)$ & $97.6(9.8)$ & $94.8(10.1)^{*}$ \\
Renal blood flow (ml min $\left.\mathrm{m}^{-2}\right)$ & $577(36)$ & $585(27)$ & $597(33)$ \\
Renal vascular resistance (units) & $82.6(6.7)$ & $70.7(5.1)^{*}$ & $69.1(4.5)$ \\
\hline
\end{tabular}

$* P<0.05$ compared with placebo 


\section{Patterns of compliance in hypertension}

\section{T. PULLAR*, S. KUMAR, S. PEAKER \& M. FEELY}

Clinical Pharmacology Unit, University Department of Medicine, General Infirmary, Leeds LS1 3EX

Despite the inaccuracies of the traditional methods for measuring compliance it has been stated that up to $75 \%$ of cases of poorly controlled blood pressure are due to poor compliance (Sackett, 1979). We have previously described compliance in a small number of unselected hypertensive patients (Feely et al., 1987a). Here we describe two pilot studies looking at compliance in specific groups of patients with hypertension which were carried out as a preliminary to a major long-term study in this area. In Study 1, 13 patients with refractory essential hypertension had a 40 day supply of one of their usual medications labelled with phenobarbitone $2 \mathrm{mg}$ and blood taken for plasma phenobarbitone estimation by h.p.l.c. after 28 days. Phenobarbitone level to dose ratio (LDR) was calculated and compared with previously derived 'normal' values (Feely et al., 1987b). We were able to confirm good compliance in eight patients who had LDRs above the median normal volunteer value and poor compliance in three with LDRs lower

Feely, M. et al. (1987a). Br. J. clin. Pharmac., 23, 595P.

Feely, M. et al. (1987b). Br. J. clin. Pharmac., 24, 77. than the lowest volunteer value. One patient with borderline LDR of 11.85 (normal range 11.9-17.4) was found after a repeat of the study to have an LDR of 7.9. The remaining patient had an LDR of 14.7 (volunteer median = 15.5; lowest $=11.9$ ) and was likely to have had good compliance. Blood pressure measurements did not suggest improved compliance during the study. In study 2,10 patients with mild/moderate hypertension were randomised to atenolol or lisinopril with the dose being titrated against response. The study was blinded using a double dummy technique and the atenolol/atenolol placebo was labelled with $2 \mathrm{mg}$ phenobarbitone. Blood was taken for phenobarbitone levels after $1,2,4,6,10,14,16$ and 26 weeks. Phenobarbitone LDRs were well within the expected range for the duration of the study in seven patients. In three patients, however, levels were well below ( $<80 \%$ of) the lowest normal volunteer value on at least one occasion although all patients had (4 week) levels within the normal volunteer range.

Thus, a large proportion of patients with refractory hypertension appear to have good compliance at times when blood pressure control is poor. In milder hypertension, although compliance is usually good some patients show evidence of prolonged periods of poor compliance.

Sackett, D. L. (1979). Can. med. Ass. J., 121, 259.

\section{The interaction between atrial natriuretic peptide (ANF99-126) and aldosterone on renal sodium handling in man}

\section{A. R. A. RAHMAN*, J. MOTWANI, C. C. LANG \& A. D. STRUTHERS \\ Department of Clinical Pharmacology, Ninewells Hospital and Medical School, Dundee DD1 9SY, Scotland}

There are several mechanisms involved in sodium and water homeostasis, one of which is the renin angiotensin system (RAAS). The main active components of this cascade are angiotensin II (AII) and aldosterone. Recently, ANF has been discovered to be another major influence on renal sodium handling. Previous studies have shown that exogenous AII can blunt the natriuretic and diuretic effects of ANF in man. Activation of endogenous RAAS by diuretic therapy has also been shown to blunt or abolish the natriuretic effect of ANF (McMurray \& Struthers, 1988). We have now studied the interaction between exogenous aldosterone and ANF on sodium and water handling. Aldosterone exerts its effect by increasing sodium reabsorption at the distal tubule. Most ANF receptors have been localised in the collecting duct. Animal data suggested that aldosterone potentiates the diuretic effect of ANF (Croxatto et al., 1987). It has also been suggested that in man, ANF may act by inhibiting the antinatriuretic effect of endogenous aldosterone.

Nine salt replete male volunteers mean age $29.8 \pm 2.2$ years $( \pm$ s.e. mean) were studied on 4 study days at least 7 days apart. Volunteers were subjected to the overhydration protocol. After an equilibration period is reached, infusions of either aldosterone $12 \mathrm{pmol} \mathrm{kg}^{-1}$ $\mathrm{min}^{-1}$ (Aldo) + placebo (P), ANF (2 pmol $\left.\mathrm{kg}^{-1} \min ^{-1}\right)+\mathrm{P}$, dual placebo $(\mathrm{P}+\mathrm{P})$ or 
Aldo + ANF were started and the infusion continued for $3 \mathrm{~h}$. Baseline sodium excretion over a $24 \mathrm{~h}$ period prior to each study day was comparable.

We have described for the first time in man that exogenous aldosterone blunts the natriuretic effect of physiological levels of ANF although not its diuretic effect. Except for a small (but significant) rise in heart rate with the aldosterone infusion, no significant changes in haemodynamics were produced by the infusions. In chronic heart failure, where there is activation of both the RAAS and ANF, the failure of ANF to exert its full natriuretic effect could be due to aldosterone's blunting ANF's natriuretic effect.

Table 1 Effect (mean \pm s.e. mean) of different infusions on sodium excretion $\left(\mathrm{UNa}^{+} \mathrm{V}\right)$, flow rate $(\mathrm{V})$, heart rate $(\mathrm{HR})$ and blood pressure

\begin{tabular}{|c|c|c|c|c|}
\hline & $P+P$ & Aldo $+P$ & $A N F+P$ & Aldo $+A N F$ \\
\hline $\mathrm{UNa}^{+} \mathrm{V}\left(\mathrm{mmol} \mathrm{min}{ }^{-1}\right)$ & $154.1 \pm 6.7$ & $112.0 \pm 6.3^{*}$ & $208.5 \pm 6.3^{*}$ & $153.4 \pm 6.3$ \\
\hline $\mathrm{V}\left(\mathrm{ml} \mathrm{min}^{-1}\right)$ & $15.7 \pm 0.3$ & $15.0 \pm 0.3$ & $18.0 \pm 0.3^{*}$ & $18.7 \pm 0.5^{*}$ \\
\hline HR (beats $\min ^{-1}$ ) & $61.0 \pm 0.6$ & $64.0 \pm 0.6^{*}$ & $61.0 \pm 0.6$ & $61.0 \pm 0.6$ \\
\hline $\mathrm{SBP}(\mathrm{mm} \mathrm{Hg})$ & $124.0 \pm 5.0$ & $121.0 \pm 5.0$ & $118.0 \pm 5.0$ & $126.0 \pm 5.0$ \\
\hline $\mathrm{DBP}(\mathrm{mm} \mathrm{Hg})$ & $73.0 \pm 0.7$ & $71.0 \pm 0.7$ & $72.0 \pm 0.7$ & $70.0 \pm 0.7$ \\
\hline
\end{tabular}

$* P<0.05$

Croxatto, H. R. et al. (1987). Potentiating effect of aldosterone on the diuretic action atrial extract. Experientia, 43, 604.

McMurray, J. \& Struthers, A. D. (1988). Frusemide pretreatment blunts the inhibition of renal tubular sodium reabsorption by ANF in man. Eur. J. clin. Pharmac., 35, 333.

\section{The potassium and magnesium sparing properties of amiloride and spironolactone}

\author{
D. L. MURDOCH*, G. FORREST, D. L. DAVIES \\ \& G. T. McINNES \\ University Department of Medicine and \\ Therapeutics, Western Infirmary, Glasgow G11 6NT
}

Published estimates of the relative potency of amiloride (A) and spironolactone (S) vary considerably (McInnes, 1982; Ramsay et al., 1980). The aim of this study was to make a quantitative comparison of the influences of amiloride and spironolactone on potassium $(\mathrm{K})$ and magnesium (Mg) status in thiazide-treated subjects. Twelve normal subjects with reductions in plasma $\mathrm{K}>0.5 \mathrm{mmol} \mathrm{l}^{-1}$ after hydrochlorothiazide (H) $100 \mathrm{mg}$ daily for 1 week entered a double-blind, randomised, balanced crossover comparison of amiloride (5 mg and $20 \mathrm{mg}$ ) and spironolactone $(25 \mathrm{mg}$ and $100 \mathrm{mg}$ ) in combination with hydrochlorothiazide $100 \mathrm{mg}$. Treatments were administered once daily for 1 week and phases were separated by 2 week intervals. Plasma and erythrocyte electrolytes

McInnes, G. T. (1982). Clin. Pharmac. Ther., 31, 472. were measured repeatedly from $09.00 \mathrm{~h}-17.00$ $h$ on the final day of each treatment phase and on the day before hydrochlorothiazide alone. The results presented are derived from the mean results for individuals on study days. Data for hydrochlorothiazide alone are included for comparison.

Treatment with hydrochlorothiazide reduced plasma $\mathrm{K}, \mathrm{RBC} \mathrm{K}$ and $\mathrm{RBC} \mathrm{Mg}$ but had no influence on plasma $\mathrm{Mg}$. Amiloride and spironolactone attenuated thiazide-induced falls in plasma potassium in a dose-related fashion: relative potency amiloride:spironolactone, 10:1 (95\% confidence intervals, 6-16:1). Only amiloride $20 \mathrm{mg}$ increased plasma $\mathrm{Mg}$ concentration. RBC electrolytes were unaffected by amiloride and spironolactone. Thus, on a weight basis, amiloride is 10 times more potent than spironolactone as a $\mathrm{K}$-sparing agent in thiazide-treated normal subjects. The clinical relevance of the influence of amiloride on plasma $\mathrm{Mg}$ is uncertain in the absence of any change after hydrochlorothiazide.

Ramsay, L. E. et al. (1980). Clin. Pharmac. Ther., 27, 533. 
Table 1 Overall mean results in 12 normal subjects

\begin{tabular}{|c|c|c|c|c|c|c|c|c|}
\hline & \multicolumn{2}{|c|}{ H 100 mg alone } & \multicolumn{4}{|c|}{ H $100 \mathrm{mg}$ plus } & \multirow{2}{*}{$\begin{array}{l}\mathrm{P} \text { between } \\
\text { treatments }\end{array}$} & \multirow{2}{*}{$\begin{array}{l}\mathrm{P} \text { between } \\
\text { compounds }\end{array}$} \\
\hline & Before & After & $A 5$ & $A 20$ & $S 25$ & $S 100$ & & \\
\hline $\begin{array}{l}\text { Plasma K } \\
\left(\mathrm{mmol} \mathrm{1}^{-1}\right)\end{array}$ & 4.05 & 3.37 & 3.55 & 3.83 & 3.46 & 3.68 & 0.001 & 0.005 \\
\hline $\begin{array}{l}\text { Plasma Mg } \\
\left(\mathrm{mmol} \mathrm{l}^{-1}\right)\end{array}$ & 0.806 & 0.810 & 0.804 & 0.837 & 0.802 & 0.789 & 0.001 & 0.003 \\
\hline $\begin{array}{l}\mathrm{RBC} \mathrm{K} \\
\left(\mathrm{mg} \mathrm{kg}^{-1} \cdot \mathrm{ds}\right)\end{array}$ & 251.2 & 240.9 & 238.8 & 238.1 & 238.6 & 240.3 & NS & NS \\
\hline $\begin{array}{l}\mathrm{RBC} \mathrm{Mg} \\
\left(\mathrm{mg} \mathrm{kg}^{-1} . \mathrm{ds}\right)\end{array}$ & 5.65 & 5.34 & 5.10 & 5.12 & 5.13 & 5.17 & NS & NS \\
\hline
\end{tabular}

\section{POSTER COMMUNICATIONS}

\section{Metabolism of cyclosporin by human gastrointestinal mucosa in vitro}

\section{J. F. TJIA, I. R. WEBBER \& D. J. BACK \\ Department of Pharmacology and Therapeutics, University of Liverpool, P.O. Box 147, Liverpool L69 3BX}

Cyclosporin (CSA) is a potent immunosuppressive agent which is widely used to prevent the rejection of transplanted organs and increasingly to treat diseases of autoimmune origin. CSA is known to undergo extensive hepatic metabolism in man to mono- and dihydroxylated as well as $N$-demethylated products (Ptachcinski et al., 1986). Poor bioavailability of CSA has generally been attributed to a) poor absorption and b) hepatic metabolism, although a study by Gridelli et al. (1986) in dogs indicated some metabolism by the gastrointestinal mucosa. The aim of our study was to examine the potential of human gastrointestinal mucosa to metabolise CSA.

Histologically normal colon was obtained from six patients undergoing resection for localised tumours. The study was approved by the Mersey Regional Hospital Ethics Committee. Mucosal sheets were prepared and mounted between four pairs of perspex chambers as previously described (Rogers et al., 1987). Radiolabelled cyclosporin ([ $\left.{ }^{3} \mathrm{H}\right]-\mathrm{CSA} ; 17 \mathrm{Ci}$

Gridelli, B. et al. (1986). Transplantation, 41, 388. Ptachcinski, R. J. et al. (1986). Clin. Pharmacokin., 11, 107. $\left.\mathrm{mmol}^{-1} ; 0.2 \mu \mathrm{Ci} ; 10 \mu \mathrm{M}\right)$ was added to each mucosal chamber. At intervals to $3 \mathrm{~h}$ aliquots of buffer were removed from the mucosal chamber for determination of CSA and metabolites. Aliquots of mucosal fluid were subjected to extraction with diethyl ether and following evaporation to dryness were redissolved in mobile phase and analysed by radiometric h.p.l.c. (Tjia et al., 1989). Metabolites were tentatively identified according to the retention times of authentic standards (M17, M21). In one study gastric mucosa was used and a similar experimental protocol to that outlined above was followed.

The overall net transport of CSA from the mucosal chamber to the serosal chamber was low $(1 \%)$. In the mucosal chamber at $3 \mathrm{~h}$ (for colon), $77.6 \pm 9.2 \%$ (mean \pm s.d.) of drug was present as CSA, $9.9 \pm 4.4 \%$ as M17 and $8.7 \pm$ $4.2 \%$ as M21. Total metabolite production was variable (range 10.1-30.6\%) and increased over the $3 \mathrm{~h}$ period of incubation. Data obtained from the single gastric mucosal sample indicated metabolism of CSA to have taken place but the metabolites did not co-chromatograph with either M17 or M21.

The findings of this study indicate that CSA is metabolised in human gut mucosa in vitro. First pass metabolism in the gut may make an important contribution to the poor systemic bioavailability of CSA seen in many patients.

Rogers, S. M. et al. (1987). Br. J. clin. Pharmac., 23, 727.

Tjia, J. F. et al. (1989). Br. J. clin. Pharmac., 28, 362. 


\section{Effect of progestogens on the metabolism of ethinyloestradiol by human liver microsomes in vitro}

\section{J. BACK, J. F. TJIA, R. HOULGRAVE \& M. L'E. ORME \\ Department of Pharmacology and Therapeutics, University of Liverpool, P.O. Box 147, Liverpool L69 3BX}

The oral contraceptive steroid (OCS) ethinyloestradiol $\left(\mathrm{EE}_{2}\right)$ is metabolized to 2-hydroxy $\mathrm{EE}_{2}\left(2-\mathrm{OHEE}_{2}\right)$, a pathway catalysed by cytochromes from the P450IIC, P450IIE and P450IIIA gene families (Ball et al., 1990; Guengerich, 1988). The work of Guengerich (1988) highlights P450IIIA4 (P450 ${ }_{N F}$ ) as the major enzyme involved and also shows $\mathrm{EE}_{2}$ to be a mechanism-based inhibitor of its own metabolism. Mechanism based or 'suicide' inactivation also occurs with other acetylenic steroids including progestogens. Since progestogens are used with $\mathrm{EE}_{2}$ in combined OCS preparations, it is important to know whether a progestogen can inactivate the isozyme(s) responsible for $\mathrm{EE}_{2}$ 2-hydroxylation. Recently Jung-Hoffman \& Kuhl (1989) have suggested, on the basis of higher $\mathrm{EE}_{2}$ plasma concentrations in women taking an OC containing $\mathrm{EE}_{2}$ and gestodene compared with those taking $\mathrm{EE}_{2}$ and desogestrel, that gestodene inhibits $\mathrm{EE}_{2}$ metabolism. We have studied the effects of gestodene and 3-keto desogestrel (3-KD; the active metabolite of desogestrel) on

Ball, S. E. (1990). Biochem. J. (in press).

Guengerich, F. P. (1988). Mol. Pharmac., 33, 500. the metabolism of $\mathrm{EE}_{2}$ in vitro.

Incubations (for $8 \mathrm{~min}$ at $37^{\circ} \mathrm{C}$ ) contained $\mathrm{EE}_{2}(25 \mu \mathrm{M} ; 0.5 \mu \mathrm{Ci})$, gestodene or $3-\mathrm{KD}$ $(0-100 \mu \mathrm{M})$ human liver microsomal protein (1.5 mg), NADPH (0.6 mM), ascorbate (1 mM) and $0.067 \mathrm{M}$ phosphate buffer ( $\mathrm{pH} 7.4$ ) to a final volume of $2.5 \mathrm{ml}$. $\mathrm{EE}_{2}$ and metabolites were extracted and quantified by radiometric h.p.l.c. A second study involved pre-incubation of the progestogens $(10$ or $100 \mu \mathrm{M})$ with microsomal protein $(250 \mathrm{pmol})$ and NADPH $(0.6 \mathrm{~mm})$ for $30 \mathrm{~min}$ in a volume of $50 \mu \mathrm{l}$. At the end of preincubation, the contents of a second tube containing $\mathrm{EE}_{2}$, ascorbate, NADPH and phosphate buffer to a total volume of $950 \mu \mathrm{l}$ were transferred to the preincubation tube. Incubation then proceeded for $8 \mathrm{~min}$.

On coincubation both gestodene and 3-KD produced some concentration-dependent inhibition of $\mathrm{EE}_{2}$ 2-hydroxylation. Mean data from five human livers showed $14.62 \%$ of 2-OHEE ${ }_{2}$ formed in the $8 \mathrm{~min}$ incubation (range 9.6-18.1\%) and this was reduced by gestodene $(100 \mu \mathrm{M})$ to $12.3 \%$ and by $3-\mathrm{KD}(100 \mu \mathrm{M})$ to $10.0 \%$. On preincubation, inhibition was greater. Inhibition with gestodene at $10 \mu \mathrm{M}$ was $28.2 \pm$ $16.7 \%(n=6)$ and at $100 \mu \mathrm{M}$ was $49.3 \pm 8.6 \%$. Inhibition with $3-\mathrm{KD}$ at $10 \mu \mathrm{M}$ was $24.3 \pm 12.2 \%$ and at $100 \mu \mathrm{M}$ was $41.6 \pm 12.2 \%$.

These studies indicate that acetylenic progestogens can inhibit cytochrome P450. However, we have not been able to show any difference between gestodene and 3-KD in this respect.

Jung-Hoffman, C. \& Kuhl, H. (1989). Contraception, 40, 299.

\section{Glucuronidation of zidovudine (azidothymidine) by human liver microsomes}

\author{
S. M. $\operatorname{SIM}^{1}$ \& D. J. BACK ${ }^{2}$ \\ ${ }^{1}$ Department of Pharmacology, University of \\ Malaya, Malaysia and ${ }^{2}$ Department of Pharmacology \\ \& Therapeutics, University of Liverpool, P.O. Box \\ 147, Liverpool L69 3BX
}

Zidovudine (3'-azido-3'-deoxythymidine), formerly known as azidothymidine (AZT) is an analogue of the naturally occurring thymidine. It is at present the only drug with proven efficacy available for patients with AIDS or ARC. In man, the drug has a short half-life of approximately $1 \mathrm{~h}$, and is eliminated mainly by hepatic glucuronidation followed by rapid renal excretion of the glucuronide metabolite, GAZT (Cload, 1989). Interference of the glucuronidation of AZT by other drugs may therefore lead to enhancement of AZT effect or to increased toxicity of the drug. Such potential interactions may be of clinical importance as patients with HIV infection frequently require treatment with prolonged and multiple drug regimens. The present study describes an in vitro method which may be useful for studying such drugdrug interactions.

Microsomes were prepared using the classical differential centrifugation method from histologically normal human livers obtained from 
kidney transplant donors. Glucuronidation of AZT was carried out in a final volume of $0.2 \mathrm{ml}$ containing $50 \mathrm{~mm}$ Tris- $\mathrm{HCl}(\mathrm{pH} \mathrm{7.5)}$, $5 \mathrm{~mm} \mathrm{MgCl}_{2}, 5 \mathrm{~mm}$ UDPGA, 4.5 to $9.5 \mathrm{mg}$ microsomal protein $\mathrm{ml}^{-1}$, and 0.25 to $10 \mathrm{mM}$ AZT. Incubations were carried out at $37^{\circ} \mathrm{C}$ for $1 \mathrm{~h}$ and terminated with $0.1 \mathrm{ml}$ acetonitrile. After centrifugation, 5 to $20 \mu$ l aliquots of the supernatants were assayed for AZT and GAZT with a reverse-phase $\mathrm{C}_{18}$ h.p.l.c. system (Good et al., 1988).

The $V_{\max }$ value obtained with liver from donor 3 was approximately twice that of other livers. This donor had been on long-term phenytoin and phenobarbitone. The glucuronidation of $\mathrm{EE}_{2}$ was also enhanced in this liver (Pacifici \& Back, 1988).

Table 1 The kinetic constants, $K_{m}$ and $V_{\max }$, for each liver studied as determined from the Eadie-Hofstee plot

\begin{tabular}{ccccc}
\hline Donor & Sex & Age (years) & $\mathrm{K}_{\mathrm{m}}(\mathrm{mM})$ & $\mathrm{V}_{\max }\left(\mathrm{nmol} \mathrm{h}^{-1} \mathrm{mg}^{-1}\right)$ \\
\hline 1 & $\mathrm{M}$ & 29 & 2.28 & 66.1 \\
2 & $\mathrm{M}$ & 27 & 2.21 & 55.8 \\
3 & $\mathrm{~F}$ & 46 & 2.97 & 109.0 \\
4 & $\mathrm{~F}$ & 17 & 3.32 & 54.4 \\
5 & $\mathrm{M}$ & 18 & 2.21 & 54.7 \\
& & mean \pm s.d. & $2.60 \pm 0.52$ & $68.0 \pm 23.4$ \\
\hline
\end{tabular}

Cload, P. A. (1989). J. Infection, 18, Supplement I, 15.

Good, S. S. et al. (1988). J. Chromatogr., 431, 123.
Pacifici, G. M. \& Back, D. J. (1988). J. steroid Biochem., 31, 345.

\section{Species difference in the in vitro bioactivation of mianserin}

P. ROBERTS, N. R. KITTERINGHAM \& B. K. PARK

Department of Pharmacology, University of Liverpool, L69 3BX

Mianserin undergoes bioactivation to a cytotoxic metabolite, in vitro, in the presence of human but not mouse microsomes (Riley et al., 1988). To explore species differences in the metabolism of mianserin, we have investigated the formation of stable, chemically reactive and cytotoxic mianserin metabolites in vitro, in the presence of human, mouse, rat, rabbit and guinea pig hepatic microsomes. Hepatic microsomes were prepared from four individual livers from each species and from four transplant donors' livers (Riley et al., 1988): cytochrome P450 content was in the normal range. Incubations consisted of microsomal protein $(0.5 \mathrm{mg})$, mianserin $(10$ $\mu \mathrm{M} ; 0.5 \mu \mathrm{Ci}),+/-\mathrm{NADPH}(1 \mathrm{~mm})$ and human mononuclear leucocytes $\left(1 \times 10^{6}\right)$ which were maintained at $37^{\circ} \mathrm{C}$ for $2 \mathrm{~h}$ in HEPES buffered medium ( $\mathrm{pH}$ 7.4). Cell death was assessed by trypan blue exclusion following a further $16 \mathrm{~h}$ incubation in drug-free medium (HEPES buffer

Table 1 The results of the study. Values are mean \pm s.d. for four determinations

\begin{tabular}{lccrc}
\hline \multicolumn{1}{c}{ Species } & $\begin{array}{c}\text { \% cell death } \\
\text { (NADPH-dependent) }\end{array}$ & \multicolumn{2}{c}{ Irreversible binding (pmol mg } \\
& & $-N A D P H$ & $+N A D P H$ & $+G S H+N A D P H$ \\
\hline Human & $* 9.96 \pm 3.75$ & $182 \pm 142$ & $712 \pm 490$ & $156 \pm 44$ \\
Mouse & $0.97 \pm 0.32$ & $202 \pm 24$ & $1520 \pm 214$ & $382 \pm 78$ \\
Rat & $2.19 \pm 0.92$ & $254 \pm 82$ & $1332 \pm 292$ & $328 \pm 34$ \\
Rabbit & $1.43 \pm 0.77$ & $242 \pm 64$ & $972 \pm 234$ & $358 \pm 78$ \\
Guinea pig & $0.38 \pm 0.19$ & $170 \pm 30$ & $1062 \pm 134$ & $226 \pm 62$ \\
\hline
\end{tabular}

${ }^{*} P<0.001$ for difference between human and all other species (ANOVA) 
containing $5 \mathrm{mg} \mathrm{ml}^{-1} \mathrm{HSA}$ ). Irreversible binding (a measure of chemically reactive metabolite formation) was measured by exhaustive solvent extraction, and stable metabolites by radiochromatography (Riley et al., 1988). Mianserin underwent extensive NADPH-dependent metabolism ( $>90 \%$ ) in microsomes from all species investigated. However, generation of a cytotoxic metabolite was only evident in the presence of human liver microsomes. In contrast, formation of chemically reactive (irreversibly bound) metabolite was similar for microsomes from all species (Table 1). Irreversible binding was significantly reduced $(P<0.05)$ by addition of glutathione $(1 \mathrm{~mm})$.

Riley, R. J. et al. (1988). Br. J. clin. Pharmac., 26, 577.

\section{Species differences in the sensitivity of metoprolol oxidation to inhibition by the quinidine/quinine isomer pair}

\section{S. LENNARD, M. ADAMS, S. V. OTTON, G. T. TUCKER \& H. F. WOODS \\ University Department of Medocine and Pharmacology, Royal Hallamshire Hospital, Sheffield S10 2JF}

Quinidine but not quinine is a potent and selective inhibitor of human debrisoquine 4-hydroxylase in vitro and in vivo. However, selective inhibition by quinidine of the rat orthologue of this enzyme does not occur (Kobayashi et al., 1989). The oxidative metabolism of metoprolol is also catalysed by human debrisoquine 4-hydroxylase (Otton et al., 1988). We have compared the effect of quinidine and quinine on (S)-metoprolol (S-M) oxidation by liver microsomes from man, dog, rabbit, rat and mouse.

Microsomes were prepared using male livers from one human renal transplant donor, one beagle dog, one rabbit (Dwarf strain), three rats (Wistar strain) and three mice (Swiss white strain). S-M was incubated with microsomes from each species at substrate concentrations $(10-40 \mu \mathrm{M})$ based on previously determined $K_{m}$ values for metabolite appearance. The production of $\alpha$-hydroxymetoprolol (HM) and $O$-demethylmetoprolol (ODM) was measured by h.p.l.c. (Otton et al., 1988). Single incubations of $\mathrm{M}$ with quinidine or quinine (concentration range 0.005 to $100 \mu \mathrm{M}$ ) were analysed in duplicate.

Microsomes from all species catalysed the formation of both $\mathbf{M}$ metabolites in the ratio ODM:HM of 3.9:1 human, 2.25:1 dog, 1.7:1 rabbit, $0.37: 1$ rat and 5:1 mouse. $\mathrm{IC}_{50}$ values $(\mu \mathrm{M})$ for inhibition by quinidine and quinine are shown in Table 1.

Quinidine was at least 10 times more potent an inhibitor of metoprolol oxidation in human microsomes than in those from any of the other species studied. Only the dog showed similar stereo-selective inhibition favouring quinidine, although the difference between the stereoisomers was much smaller. In contrast, quinine was more potent as an inhibitor in the rabbit, rat and mouse. The data provide further evidence that the catalytic site of human debrisoquine 4-hydroxylase has different characteristics from those of other species.

Table 1

\begin{tabular}{lcccc}
\hline & \multicolumn{2}{c}{$H M$} & \multicolumn{2}{c}{ ODM } \\
& Quinidine & Quinine & Quinidine & Quinine \\
\hline Human & 0.05 & 10 & 0.02 & 20 \\
Dog & 0.58 & 1.3 & 0.4 & 1.5 \\
Rabbit & 14 & 4.7 & 20.5 & 17.5 \\
Rat & 2.6 & 0.2 & 6 & 4 \\
Mouse & $>100$ & $>100$ & 23 & 4 \\
\hline
\end{tabular}

Kobayashi, K. et al. (1989). Biochem. Pharmac., 36, Otton, S. V. et al. (1988). J. Pharmac. exp. Ther., 2795. 
Childhood acute lymphoblastic leukaemia: pharmacogenetic variation in response to 6-mercaptopurine

\author{
L. LENNARD, J. S. LILLEYMAN ${ }^{1}$, J. VAN \\ LOON $^{2}$ \& R. M. WEINSHILBOUM ${ }^{2}$ (introduced \\ by M. S. LENNARD) \\ Department of Medicine and Pharmacology, The \\ Royal Hallamshire Hospital, Sheffield S10 2JF, \\ ${ }^{1}$ Department of Haematology, The Children's \\ Hospital, Sheffield S10 2TH and ' Department of \\ Pharmacology, The Mayo Clinic, Rochester, MN \\ 55905, USA
}

6-Mercaptopurine (6-MP) is an important drug for continuing the remission achieved by other agents in childhood acute lymphoblastic leukaemia (ALL), and red blood cell 6-thioguanine nucleotides (6-TGN) can be used as an indirect measure of 6-MP cytotoxicity (Lennard \& Lilleyman, 1989). Thiopurine methyltransferase (TPMT) catalyses the S-methylation of 6-MP, and TPMT activity is controlled by a common genetic polymorphism (Weinshilboum \& Sladek, 1980). An alternative metabolic route leads to the formation of cytotoxic 6-TGN. To test the hypothesis that these two pathways might compete with each other in a way which could affect the therapeutic response to 6-MP, intracellular 6-

Lennard, L. \& Lilleyman, J. S. (1989). J. clin. Oncol., 7, 1816.
TGN concentrations and TPMT enzymatic activity were measured in blood samples from 95 children receiving long-term 6-MP therapy for ALL. TPMT activities were also measured in blood samples from 130 control children and 104 long survivors of ALL off treatment.

In the 95 children on 6-MP there were wide interindividual differences in red cell 6-TGN concentrations at the full protocol dose of 75 $\mathrm{mg} \mathrm{m}^{-2}$, and these were negatively correlated with red cell TPMT activity $\left(r_{\mathrm{s}}=-0.5, P<\right.$ 0.0005 ). Children with 6-TGN concentrations below the group median had higher TPMT activities $(P<0.0001)$ and a higher subsequent relapse rate (logrank $\left.\chi^{2}=11.1, P<0.001\right)$. Of the 104 long survivors, 50 had been treated on the 'gentle' low-dose 6-MP protocols used in the United Kingdom before 1980 . This subgroup of survivors contained an excess of children with lower TPMT activities compared with normal controls $\left(\chi^{2}=11.3\right.$, d.f. $\left.=6, P<0.01\right)$. Finally, patients on prolonged treatment with 6-MP had higher TPMT activities than did normal controls $(P<0.00001)$.

These results indicate that genetically determined TPMT activity is a substantial regulator of the cytotoxic effect of 6-MP, an effect which is in turn important for the success of conventional therapy for childhood ALL.

Weinshilboum, R. M. \& Sladek, S. L. (1980) Am. J. Hum. Genet., 32, 651.

\section{Measurement of epidoxorubicin and its metabolites by h.p.l.c. and advanced automated sample processor (AASP) in patients with abnormal liver biochemistry}

N. A. DOBBS, L. A. SUMMERS \& C. J.

TWELVES (introduced by B. V. ROBINSON) Department of Pharmacology and Clinical Oncology Unit, Guy's Hospital, London SE1 9RT

Epidoxorubicin is a 4-OH epimer of doxorubicin with a wide range of antitumour activity. We have measured the drug and its six metabolites in plasma by a new h.p.l.c. technique. Epidoxorubicin and metabolites were isolated from plasma by sorbent extraction onto C2-ethyl cassettes (Varian R) which had been conditioned with methanol, water and buffer $\left(\mathrm{NaH}_{2} \mathrm{PO}_{4} /\right.$ acetonitrile; $\left.9: 1 \mathrm{v} / \mathrm{v}\right)$. The prepared cassettes were then loaded into the AASP which introduced each cartridge into the h.p.l.c. solvent stream $\left(0.19 \mathrm{M} \mathrm{NaH} \mathrm{PO}_{4} /\right.$ acetonitrile; 2.25:1 v/v) with a $10 \mathrm{ml} \mathrm{min}^{-1}$ flow rate. The precolumn was Lichrosorb RP $1810 \mu(5 \mathrm{~cm} \times$ $5 \mathrm{~mm}$ ) and the analytical column was Apex ODS $5 \mu(10 \mathrm{~cm} \times 5 \mathrm{~mm})$. Fluorescence detection (excitation $480 \mathrm{~nm}$, emission $580 \mathrm{~nm}$ ) was used with daunorubicin as the internal standard. The detection limit was $2-4 \mathrm{ng} \mathrm{ml}^{-1}$ for epidoxorubicin and all metabolites.

Eleven patients with advanced breast cancer (two with normal liver biochemistry, nine who had liver metastases and a raised aspartate transaminase (AST) received epidoxorubicin $25 \mathrm{mg} \mathrm{m}^{-2}$ i.v. weekly. The area under the concentration-time curve to $48 \mathrm{~h}$ (AUC) was calculated for epidoxorubicin and its metabolites using the trapezoidal method and terminal half- 
life $\left(t_{1 / 2}\right)$ for epidoxorubicin was estimated using a three compartment model.

For epidoxorubicin, both AUC (Figure 1) and $t_{1 / 2}$ correlated strongly with AST $(r=0.83$ and $r=0.87$ respectively). There was also a strong correlation between AST and AUC for epidoxorubicinol $(r=0.79)$. However, the correlation between AST and AUC for epirubicin glucuronide $(r=0.47)$ and epidoxorubicinol glucuronide $(r=0.57)$ was weaker. Moreover, AST did not influence the time taken to achieve maximum plasma concentrations of these metabolites.

Using a new h.p.l.c. technique we have shown that serum AST influences exposure to epidoxorubicin and epidoxorubicinol, but does not have a significant effect on the formation of the glucuronide metabolites.

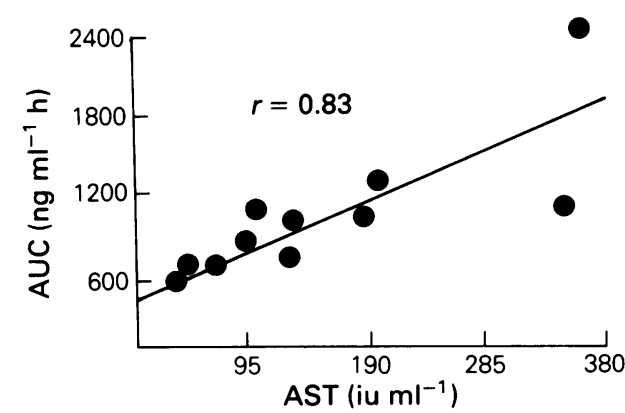

Figure 1 Correlation between AUC for epidoxorubicin and AST.

We are grateful to Dr P. Harper and the Hans Oppenheimer trust for financial support for NAD and LAS, and to Dr M. A. Richards and Professor R. D. Rubens for access to their patients.

\section{Indomethacin - pharmacokinetic profile and renal effects after chronic dosing in elderly patients and young volunteers}

\author{
A. P. PASSMORE ${ }^{1}$, J. C. McELNAY ${ }^{2}$, V. L. S. \\ CRAWFORD $^{1}$, J. G. MCCONNELL ${ }^{3}$, I. C. \\ TAYLOR $^{3}$ \& F. S. WALKER ${ }^{4}$ \\ ${ }^{1}$ Department of Geriatric Medicine, ${ }^{2}$ Department of \\ Pharmacy, The Queen's University of Belfast, \\ ${ }^{3}$ Geriatric Medical Unit, Ulster Hospital, Belfast and \\ ${ }^{4} \mathrm{AH}$ Robins Co Ltd, England
}

Nonsteroidal anti-inflammatory drugs are commonly prescribed for elderly patients. The steady state pharmacokinetics of indomethacin (IND) in older patients has not been documented. Treatment with IND may result in impaired renal function. This study was designed to compare the steady state pharmacokinetics of a new formulation of IND (AHR) with a standard formulation IND (MSD), and to examine the effects of both formulations on renal function in elderly patients $(E)$ and young volunteers $(\mathrm{Y})$. Twelve elderly patients $(7 \mathrm{M}$,
$5 \mathrm{~F}, 70-88$ years) with osteoarthritis and 12 healthy volunteers $(4 \mathrm{M}, 8 \mathrm{~F}, 20-34$ years) were enlisted, having given full informed consent to the protocol which was approved by the local ethics committee. According to a single blind crossover design, subjects received IND (AHR) or IND (MSD) $25 \mathrm{mg}$ three times daily for 6 days. On day 7 subjects attended after an overnight fast, the final dose was given, and blood sampled serially for $12 \mathrm{~h}$. A light breakfast was provided at $1.5 \mathrm{~h}$ and meals at $4 \mathrm{~h}$ and $8 \mathrm{~h}$. Kinetic parameters $C_{\min }, C_{\max }, t_{\max }$ and AUC 0-12 h were determined. A 7 day interval was allowed between treatment periods. In the morning of days 1 and 7 of each study period subjects were weighed, and blood drawn for estimation of urea (U), creatinine (C) and potassium $(\mathrm{K})$. Creatinine clearance $\left(\mathrm{CL}_{\mathrm{Cr}}\right)$ was calculated using a nomogram (Hull et al., 1981). Results were compared using analysis of variance and covariance with repeated measures using BMDP statistical package.

There were no differences in the pharmacokinetic parameters between formulations nor

Table 1

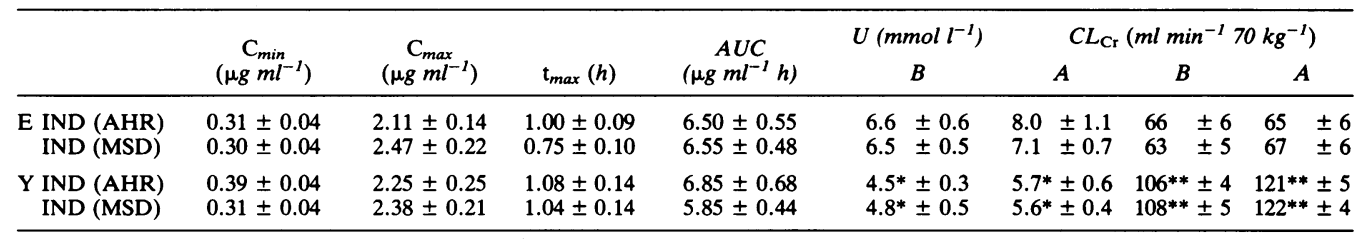

$* P<0.05,{ }^{*} P<0.01, \mathrm{Y}$ vs $\mathrm{E}, \mathrm{B}=$ before IND, $\mathrm{A}=$ after IND 
between $\mathrm{Y}$ and $\mathrm{E}$. $\mathrm{U}$ was lower in $\mathrm{Y}$ than $\mathrm{E}$ $(P<0.05)$ before and after IND, but IND had no effect in either age group. $\mathrm{CL}_{\mathrm{Cr}}$ was lower in $\mathrm{E}(P<0.01)$ than $\mathrm{Y}$ before and after IND but there were no changes due to IND. Weight and $\mathrm{K}$ were not different in $\mathrm{Y}$ or $\mathrm{E}$ before or

Hull, J. H. et al. (1981). Clin. Pharmac. Ther., 29, 516. after IND.

The steady state pharmacokinetics of IND did not differ in young and elderly subjects or with either formulation. Under the present study conditions renal function was unaffected by indomethacin.

\section{The onset of effect of the $\mathrm{H}_{1}$-receptor antagonist acrivastine assessed by histamine bronchial challenge in volunteers}

P. E. ROLAN, S. C. PHILLIPS, S. J. GRAY, J. E. PARKER, J. ADAMS \& J. POSNER

Wellcome Research Laboratories, Langley Court, Beckenham, Kent BR3 3BS

Since many patients prefer to use $\mathrm{H}_{1}$-receptor antagonists intermittently for symptomatic relief of allergic disorders, a rapid onset of action is desirable. The onset of effect of acrivastine, an $\mathrm{H}_{1}$-receptor antagonist with low sedative potential, was investigated using histamine bronchial challenge in sensitive volunteers.

Airway sensitivity to histamine inhaled for $2 \mathrm{~min}$, was assessed in 21 men and women. Partial expiratory flow volume loops were used to determine the concentration which reduced expiratory flow at $30 \%$ remaining vital capacity $\left(V \max _{30 \mathrm{p}}\right)$ by $50 \%\left(\mathrm{PC}_{50}\right)$. Fifteen subjects with $\mathrm{PC}_{50}<8 \mathrm{mg} \mathrm{ml}^{-1}$ proceeded to the main study. On each study day histamine challenge was performed starting at each individual's original $\mathrm{PC}_{50}$, doubling concentrations every 3 min until $V \max _{30 \mathrm{p}}$ had fallen by $50 \%$ from baseline or 8 $\times \mathrm{PC}_{50}$ had been reached. Subjects received capsules $90,60,45$ and 30 min before challenge. According to a randomised, balanced, doubleblind, cross-over design, one capsule contained acrivastine $8 \mathrm{mg}$ and the others lactose on four occasions (A90, A60, A45, A30) and all contained lactose on a fifth occasion (PLA). Percentage changes in $V \max _{30 p}$ on each treatment were compared by ANOVA.

The final histamine concentration $\left(8 \times \mathrm{PC}_{50}\right)$ was reached in all subjects on acrivastine in contrast to only one subject on placebo. At the lowest histamine concentrations all active treatments significantly reduced the fall in $V \max _{30 p}$ compared with placebo. There were no significant differences between any of the acrivastine treatments at either $\mathrm{PC}_{50}$ or $8 \times \mathrm{PC}_{50}$. Comparison of \% falls in $V \max _{30 \mathrm{p}}$ at $8 \times \mathrm{PC}_{50}$ on active treatment with those at $\mathrm{PC}_{50}$ on placebo showed significantly less bronchoconstriction on active treatment. Since the concentration differed by eight-fold, the effect of acrivastine at all times is equivalent to at least an eight-fold shift in the histamine dose-response curve, which compares favourably with other $\mathrm{H}_{1}$-receptor antagonists. In conclusion, a clinically desired degree of $\mathrm{H}_{1}$-receptor antagonism was present within 30 min of ingestion of the recommended therapeutic dose of acrivastine (Rafferty \& Holgate, 1987).

Table 1

\begin{tabular}{lrcccc}
\hline Mean \% change in max $_{30 p}$ from baseline & \multicolumn{3}{c}{ Mean difference and $95 \%$ CI between treatments } \\
& $P C_{50}$ & $8 \times P C_{50}$ & $A-P L A\left(P C_{50}\right)$ & $A-A 30\left(8 \times P C_{50}\right)$ & $A$ at $8 \times P C_{50}-P L A$ at $P C_{50}$ \\
\hline PLA & -32.7 & $-82.2(n=1)$ & - & & \\
A30 & -3.3 & $-11.9=1)$ & $29.5(18.1,40.8)$ & & $20.8(7.1,34.4)$ \\
A45 & 4.7 & -14.7 & $37.4(26.0,48.8)$ & $-2.8(-17.7,12.1)$ & $18.0(4.3,31.6)$ \\
A60 & -1.0 & -12.8 & $31.8(20.1,43.4)$ & $-0.9(-15.8,14.0)$ & $19.9(6.2,33.6)$ \\
A90 & 2.9 & -14.1 & $35.7(24.0,47.3)$ & $-2.2(-17.2,12.7)$ & $18.6(4.9,32.2)$ \\
\hline
\end{tabular}

Rafferty, P. \& Holgate, S. T. (1987). Am. Rev. resp. Dis., 135, 181. 


\section{Comparison of extrapulmonary $\beta$ - adrenoceptor responses to inhaled salbutamol and isoprenaline in young and elderly subjects}

\section{B. J. LIPWORTH, B. F. TREGASKIS \& D. G. McDEVITT \\ Department of Clinical Pharmacology, Ninewells Hospital and Medical School, Dundee, Scotland.}

The ageing process is accompanied by raised levels of plasma noradrenaline, and a reduction in isoprenaline-induced lymphocyte adenylatecyclase activity (Krall et al., 1981). This might suggest that the elderly have subsensitivity of $\beta_{1^{-}}$and $\beta_{2^{-}}$-adrenoceptor responses. The purpose of the present study was to compare in vivo responses to $\beta_{2}$-selective (salbutamol) and non-selective (isoprenaline) adrenoceptor agonists, in young ( $n=10$, age $23 \pm 1$ years) and elderly ( $n=7$, age $71 \pm 2$ years) subjects. Cumulative doubling doses of inhaled salbutamol and isoprenaline $(500-4000 \mu \mathrm{g})$, or placebo were given by a pear-shaped spacer, at weekly intervals, in a single-blind randomised cross-over design. Plasma potassium, electrocardiographic ( $R-R, T$ wave, $\mathrm{Q}-\mathrm{Tc})$ and blood pressure responses were measured at baseline (after a 30 min resting period) and subsequently at each dose-step (15 min for salbutamol and $5 \mathrm{~min}$ for isoprenaline). Comparisons between treatments (within each group of subjects) were made by two-way ANOVA. Comparison between young and elderly groups was by unpaired Student's $t$ test.

There were no differences between baseline values for each of the three study days within each subject group. Hypokalaemia was greater in response to salbutamol compared with isoprenaline in both young (as change from baseline, mean \pm s.e. mean): $-0.61 \pm 0.10 v \mathrm{~s}$ $0.10 \pm 0.08 \mathrm{mmol} \mathrm{l}^{-1}(P<0.01)$; and in the

Krall, J. F. et al. (1981). J. clin. Endocrinol. Metab., $52,863$. elderly: $-0.68 \pm 0.06 v s-0.20 \pm 0.10 \mathrm{mmol}$ $1^{-1}(P<0.01)$. There were no differences between young and elderly responses. $T$ wave amplitude fell significantly in response to salbutamol and isoprenaline, although this effect was progressively attenuated with increasing doses of isoprenaline. Maximum $T$ wave response was greater with salbutamol than isoprenaline in both the young (change from baseline): $-0.22 \pm 0.05$ vs $0.11 \pm 0.02$ $\mathrm{mV}(P<0.05)$; and in the elderly: $-0.17 \pm$ $0.04 v s-0.08 \pm 0.02 \mathrm{mV}(P<0.05)$; and there were no significant differences between the two groups of subjects. There were no significant differences between the effects of isoprenaline and salbutamol on Q-Tc prolongation or heart rate (isoprenaline $v s$ salbutamol): $28 \pm 4$ vs $24 \pm 4$ beats $\mathrm{min}^{-1}$ (young), $34 \pm 7$ vs $39 \pm 5$ beats min $^{-1}$ (elderly), although the chronotropic effect of salbutamol was significantly greater in the elderly $(P<$ $0.05)$. There were larger increases in SBP in response to isoprenaline compared with salbutamol, which were significant in the young: $14 \pm 3$ vs $6 \pm 2 \mathrm{~m} \mathrm{mHg}(P<0.05)$, but not in the elderly: $8 \pm 4$ vs $3 \pm 2 \mathrm{~mm} \mathrm{Hg}$. Falls in DBP were greater in the elderly in response to isoprenaline (elderly $v s$ young): $-9 \pm 2 v s 2$ $\pm 2 \mathrm{~mm} \mathrm{Hg}(P<0.001)$, and also in response to salbutamol: $-8 \pm 1$ vs $-4 \pm 1 \mathrm{mmHg}(P<$ $0.05)$.

The results of the present study suggest that inhaled isoprenaline is a less potent stimulant of extrapulmonary $\beta_{2}$ receptors compared with salbutamol, but has a greater effect on cardiac $\beta_{1}$ receptors. This would explain why isoprenaline did not cause a greater chronotropic effect than salbutamol, and why hypokalaemia was greater with salbutamol. Furthermore, there was no evidence of a decline with ageing in the function of $\beta_{1}$ or $\beta_{2}$ adrenoceptors.

\section{Effect of sulindac on the cough reflex of healthy subjects}

\author{
G. FOSTER, W. W. YEO \& L. E. RAMSAY \\ University Department of Medicine and \\ Pharmacology, Royal Hallamshire Hospital, \\ Sheffield S10 2JF
}

Persistent dry cough is a common side-effect of ACE inhibitors, with an incidence of approximately $15 \%$ (Yeo \& Ramsay, 1989). The cough is alleviated by treatment with the NSAID sulindac, suggesting that it may be mediated by prostaglandins (Choudry et al., 1989). It is not clear whether suppression of cough by sulindac 
is specific to ACE inhibitor-induced cough, or a non-specific effect on the cough reflex. We have examined the effect of sulindac on the cough reflex of healthy subjects.

Eighteen healthy subjects (9 M, $9 \mathrm{~F}$; age range 21-46 years) who had taken no prostaglandin synthetase inhibitor for 14 days consented to a double-blind balanced two phase crossover study comparing a single dose of sulindac $200 \mathrm{mg}$ with placebo. Treatment phases were separated by 1 week. The cough reflex was examined $4 \mathrm{~h}$ after dosing by administering in random order single breaths of saline or capsaicin in nine log incremental doses from 0.025-6.25 nmol using DeVilbiss No 40 nebulisers. The response was recorded as number of coughs per minute following each dose. Responses to capsaicin after sulindac and placebo were compared by examining the logdose response curves, D5 (dose required to produce 5 coughs $\min ^{-1}$ ), and threshold, peak, and cumulative responses to capsaicin. The analysis of Hills \& Armitage (1979) was used, and showed no treatment-period interaction.

The dose-response curves for capsaicin after sulindac and placebo are shown in Figure 1 for 16 subjects who could tolerate all doses of capsaicin. Sulindac had no obvious effect on the response. Sulindac and placebo did not differ

Choudry, N. et al. (1989). Br. J. clin. Pharmac., 27, 657P.

Hills, A. \& Armitage, P. (1979). Br. J. clin. Pharmac., 8, 7.

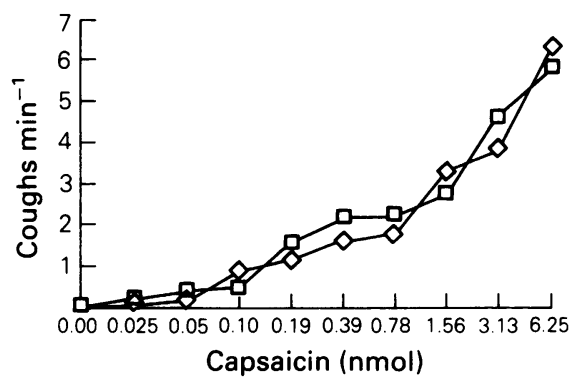

Figure 1 Effect of sulindac $(\diamond)$ and placebo $(\square)$ on cough reflex.

in comparisons $(n=18)$ of: D5 placebo 3.02 nmol, sulindac 3.40 nmol: peak response placebo 7.1 coughs $\min ^{-1}$, sulindac 8.4 coughs $\mathrm{min}^{-1}$ : and total response placebo 22.4 coughs, sulindac 23.6 coughs. The $95 \%$ CI for the difference between sulindac and placebo for total cough in response to capsaicin were -2.7 : +5.0 , indicating that sulindac is unlikely to reduce total cough by more than $12 \%$. However sulindac altered the threshold for cough in response to capsaicin from $0.49 \mathrm{nmol}$ (placebo) to $0.99 \mathrm{nmol}(P<0.05)$. A single dose of sulindac $200 \mathrm{mg}$ has a significant effect on the threshold of the cough reflex in healthy subjects.

Yeo, W. W. \& Ramsay, L. E. (1989). J. Hypertension, $7,928$.

was carried out using exercise-ECG and $24 \mathrm{~h}$ ECG-monitoring in 10 male patients with angiographically proven coronary artery disease ( $\geq 70 \%$ stenosis in one or more vessels). Anti-anginal, antihypertensive, digitalis and anti-arrhythmic drugs were stopped prior to a run-in period. Exercise testing for 4-6 min (according to Kaltenbach) was carried out 6 and $24 \mathrm{~h}$ after the first and fourth dose of placebo or test drug with a 3 day wash-out period at crossover. Maximal heart rate, maximal systolic blood pressure (SBP), maximal ST-segment depression (ST-max) during exercise measured in the ECG and 24$h$ ECG, and area under the trend plot (AUC-ST) of the $24 \mathrm{~h}$ ECG record (Oxford Medilog $4500 \mathrm{Mk}$ II) during exercise testing $24 \mathrm{~h}$ post-dose on day 1 and day 4 are shown (Table 1). The indices of ischaemia showed a marked drug and placebo effect after the first dose but by day 4 all indices after placebo had once daily in the morning. The investigation 
worsened, whereas after nifedipine the antiischaemic effect was maintained or even increased.

When the anti-ischaemic effect was greatest $(24 \mathrm{~h}$ post-dose, day 4$)$ the exercise blood pressure was similar to that after placebo indicating that the anti-ischaemic effect of this nifedipine formulation is not solely due to a drop in afterload. Although the input-rate of nifedipine in this formulation is slow, maximum heart rate after exercise was increased significantly $6 \mathrm{~h}$ post-dose $\left(+12\right.$ beats $\mathrm{min}^{-1}$ on day 1 ; +8 beats $\min ^{-1}$ on day 4 ). In conclusion, this slow release formulation administered at a dose rate of $60 \mathrm{mg}$ daily, in comparison with placebo, has a demonstrable anti-ischaemic action and this is maintained for at least $24 \mathrm{~h}$ post-dose.

Table 1

\begin{tabular}{lrrrrr}
\hline & \multicolumn{3}{c}{ Placebo } & \multicolumn{2}{c}{ Slow-release nifedipine } \\
Measured parameter & $\mathrm{n}$ & Day 1 & Day 4 & Day 1 & Day 4 \\
\hline Heart rate (beats min $^{-1}$ ) & 10 & $123 \pm 15$ & $123 \pm 15$ & $126 \pm 17$ & $122 \pm 14$ \\
SBP $_{\max }(\mathrm{mm} \mathrm{Hg})$ & 10 & $169 \pm 26$ & $171 \pm 30$ & $156 \pm 27$ & $167 \pm 29$ \\
ST-max (mm) & 10 & $1.3 \pm 0.9$ & $1.9 \pm 0.8$ & $1.1 \pm 0.8$ & $1.1 \pm 0.5^{* *}$ \\
ST-max (24 h ECG) (mm) & 7 & $2.0 \pm 0.6$ & $2.5 \pm 0.7$ & $2.0 \pm 0.7$ & $1.7 \pm 0.4^{* *}$ \\
AUC-ST (24h ECG) (mm.min) & 7 & $13.4 \pm 6.1$ & $20.0 \pm 7.6$ & $14.7 \pm 6.7$ & $14.1 \pm 3.0^{* *}$ \\
\hline
\end{tabular}

${ }^{* *} P<0.05$ vs placebo

\section{The effects of co-administration of food or antacid on the pharmacokinetics of renzapride}

A. J. WEBB, D. M. AL-AZAWIE, B. E. DAVIES, S. M. COOPER, D. QUINLAN \& B. D. C. ARNOLD (introduced by C. M. KAYE)

Beecham Pharmaceuticals Research Division, Harlow, Essex, CM19 5AD

Renzapride, 4-amino-5-chloro-2-methoxy- $N$ [4(1-azabicyclo-[3,3,1]nonyl)benzamide] is a novel compound which stimulates gastric motility without causing CNS dopamine block or prolactin release. A three part cross-over study was performed to determine the effects of coadministration of food and the co-administration of Asilone (an antacid) on the pharmacokinetics of oral renzapride. Twelve healthy male volunteers (age $32 \pm 5$ years, weight $80 \pm$ $13 \mathrm{~kg}$ ) were administered a single $1 \mathrm{mg}$ oral dose of renzapride alone, with a standard meal or with two Asilone tablets. Plasma samples were obtained predose and up to $24 \mathrm{~h}$ after each dose of renzapride. The plasma samples were assayed for renzapride by radioimmunoassay (Al-Azawie et al., 1990). The pharmacokinetic parameters $C_{\max }, t_{\max }$ and AUC were calculated and the equivalence of the co-administration of food or Asilone when compared with fasted volunteers was tested by calculating the $90 \%$ confidence interval for the mean ratio of each treatment.

The mean \pm s.d. pharmacokinetic parameters are given in Table 1 .

The presence of food more than doubled the time to reach maximum observed plasma concentration $\left(t_{\max }\right)$, the $C_{\max }$ values showed an increase of $33 \%$ and the AUC values an increase of $19 \%$ compared with the values in fasting subjects. An increase in $t_{\max }$ of $42 \%$ was observed when volunteers received Asilone tablets concurrently with renzapride. However, the $C_{\max }$ and AUC values were equivalent (the $90 \%$ confidence intervals were contained within $\pm 20 \%$ ) to those obtained when renzapride was

Table 1 Pharmacokinetic parameters of renzapride (mean \pm s.d.) in eleven subjects following oral administration of a single $1 \mathrm{mg}$ dose

\begin{tabular}{rrrrrrrrrr}
\hline \multicolumn{3}{c}{$\mathrm{C}_{\max }\left(\mathrm{ng} \mathrm{ml^{-1 } )}\right.$} & \multicolumn{3}{c}{$\mathrm{t}_{\max }(h)$} & \multicolumn{4}{c}{ AUC $\left(\mathrm{ng} \mathrm{ml}^{-1} h\right)$} \\
Fasted & \multicolumn{1}{c}{ Food } & Asilone & Fasted & Food & Asilone & Fasted & Food & Asilone \\
\hline 2.43 & 3.17 & 2.41 & 1.15 & 2.45 & 1.64 & 18.1 & 21.3 & 18.9 \\
\pm 0.66 & \pm 0.62 & \pm 0.64 & \pm 0.66 & \pm 0.65 & \pm 0.73 & \pm 4.6 & \pm & 4.2 & \pm \\
\hline
\end{tabular}


administered in the fasting state. One volunteer was withdrawn from the study due to adverse events. In future studies renzapride should be

Al-Azawie, D. M. et al. (1990). Br. J. clin. Pharmac., 29, 618P. given in the absence of food to minimise effects on $t_{\max }$. Concurrent administration with Asilone is acceptable.

\section{Verapamil serum protein binding properties: quantitation and classification}

\section{B. G. WOODCOCK, J. PIEHL \& N. RIETBROCK Department of Clinical Pharmacology, University Clinic, D-6000 Frankfurt/Main 70, FRG}

Verapamil binds to albumin and $\alpha_{1}$-acid glycoprotein $\left(\alpha_{1}\right.$-AGP). The quantitative importance of these two proteins is however unclear and no attempt has been made hitherto to characterise the binding properties of verapamil according to proposed classification schemes (Tillement et al., 1984). We have determined the binding parameters and displacement reactions for verapamil in vitro using equilibrium dialysis with serum, pure albumin (Biotest, FRG), pure $\alpha_{1}$-AGP (Sigma) and a combination of albumin and $\alpha_{1}$-AGP. Dialysis chambers $(1 \mathrm{ml})$ contained $0.75 \mathrm{ml}$ protein solution (albumin $40 \mathrm{~g}$ $1^{-1} ; \alpha_{1}$-AGP $0.9 \mathrm{~g} \mathrm{l}^{-1}$ ) or buffer at $\mathrm{pH}$ 7.4. The membrane had a 'cut-off' at 12000 Daltons. The concentration of verapamil was determined using $\left[{ }^{14} \mathrm{C}\right]$-verapamil (Knoll A G, Ludwigs- haven). At therapeutic drug concentrations $\left(0.05-0.4 \mu \mathrm{g} \mathrm{ml}^{-1}\right)$ verapamil is $90 \%$ bound in serum where both high and low affinity binding sites are present $\left(K=1.26 \times 10^{5} \mathrm{M}^{-1}\right.$ and $K=$ $\left.1.83 \times 10^{3} \mathrm{M}^{-1}\right)$. Binding to purified albumin was $55 \%$ which is in accord with data for verapamil racemate and enantiomers observed by others. One molecule $\alpha_{1}$-AGP binds one molecule verapamil at concentrations of $0.9 \mathrm{~g} \mathrm{l}^{-1}$ and 0.2 $\mu \mathrm{g} \mathrm{ml}^{-1}$ respectively $\left(K=5.85 \times 10^{4} \mathrm{M}^{-1}\right)$. The percentage binding of $\alpha_{1}$-AGP under these conditions was $62 \%$. In albumin $\left(40 \mathrm{~g} \mathrm{l}^{-1}\right)+$ $\alpha_{1}$-AGP $\left(0.9 \mathrm{~g} \mathrm{l}^{-1}\right)$ the fraction bound to albumin is approximately double that bound to $\alpha_{1}$-AGP but the total fraction bound is $20-20 \%$ lower than in serum in agreement with previous studies showing significant verapamil binding to lipoproteins in human serum. Propranolol, digitoxin, digoxin and palmitic acid (up to 100 -fold excess) had little or no effect on verapamil binding to albumin or serum. These results show that verapamil binding closely resembles that for imipramine rather than erythromycin of Group V (Table 1).

Table 1 Plasma-protein binding properties of verapamil

\begin{tabular}{lccc}
\hline $\begin{array}{l}\text { Classification group } \\
\text { Reference drug }\end{array}$ & $\begin{array}{c}V \\
\text { erythromycin }\end{array}$ & $\begin{array}{c}\text { VI } \\
\text { imipramine }\end{array}$ & $\begin{array}{c}(\text { VI) } \\
\text { verapamil }\end{array}$ \\
\hline $\mathrm{pK}_{\mathrm{a}}$ & 8.8 & 9.5 & 8.9 \\
Binding proteins & albumin (ns) & albumin (ns) & albumin (ns) \\
in plasma & $\alpha_{1}-\mathrm{AGP}(\mathrm{s})$ & $\alpha_{1}-\mathrm{AGP}(\mathrm{s}), \mathrm{Lp}$ & $\alpha_{1}-\mathrm{AGP}(\mathrm{s}), \mathrm{Lp}$ \\
Saturation in plasma & possible & ns & ns \\
Displacement by drugs & possible & no & no \\
Displacement by FFA & no & no & no \\
\hline
\end{tabular}

$\mathrm{ns}=$ non-saturable binding, $\mathrm{s}=$ saturable binding, $\mathrm{Lp}=$ lipoproteins

Tillement, J. P. et al. (1984). Adv. Drug Res., 13, 60. 
Relative bioavailability of a novel nifedipine sublingual spray in comparison with a sublingual capsule

\author{
S. EAGLE, G. ACTON, K. MANCHEE, I. \\ MEINEKE, C. DE MEY \& C. BROOM \\ Clinical Pharmacology Department, SK\&F, Welwyn \\ and Goettingen, West Germany
}

Biting a nifidipine capsule and retaining the contents sublingually is often recommended for rapid relief of acute anginal episodes. We report the results of a study, involving a novel sublingual nifedipine spray, designed to assess the pharmacokinetics and effects on supine haemodynamics, in healthy subjects, in comparison with sublingual administration from standard nifedipine capsules.

Twelve healthy volunteers $(4 \mathrm{M}, 8 \mathrm{~F})$, mean age 28 years (range 22-41) and mean weight $66.6 \mathrm{~kg}$ (range 49.1-86.3) participated in an open, randomised three way crossover study. Each received three treatments, separated by at least $48 \mathrm{~h}$ : nifedipine capsule (Adalat ${ }^{\circledR}$, Bayer), nifedipine spray $2.5 \mathrm{mg}$, nifedipine spray $5.0 \mathrm{mg}$ (Unipack, Austria). On each occasion subjects attended the Clinical Pharmacology Unit at approximately $08.00 \mathrm{~h}$ fasted from the previous midnight. Subjects rested semi-supine and an intravenous cannula was inserted. Three baseline automated pulse rate (PR) and blood pressure (BP) measurements were obtained at $5 \mathrm{~min}$ intervals and a control blood sample taken for nifedipine assay. Each treatment was then administered sublingually. The capsule was crunched, placed under the tongue and retained for $2 \mathrm{~min}$ before swallowing. The nifedipine spray was delivered as a single shot (either 2.5 or $5.0 \mathrm{mg}$ nifedipine as appropriate) under the tongue and retained for $2 \mathrm{~min}$ without swallowing. Post treatment BP and PR were measured every $5 \mathrm{~min}$ for $1 \mathrm{~h}$ and every $10 \mathrm{~min}$ for the subsequent $3 \mathrm{~h}$. Plasma concentrations of nifedipine were measured up to $8 \mathrm{~h}$ post treatment by h.p.l.c. From individual plasma concentration-time courses, $C_{\max }, t_{\max }$ and AUC (combined linear/log linear trapezoidal rule) up to the last quantifiable time point (AUC $(0, t)$ ) were derived. Dose adjusted $C_{\max }$ and AUC $(0, t)$ were examined by analysis of variance and point estimates of treatment ratios and $95 \%$ confidence intervals derived. Table 1 shows the dose adjusted pharmacokinetic comparisons for each treatment (Treatment A: $5 \mathrm{mg}$ capsule, B: $2.5 \mathrm{mg}$ spray, C: $5 \mathrm{mg}$ spray).

These results suggest comparable systemic exposure to nifedipine from both capsule and spray formulations. Relative to the capsule, significantly higher mean peak concentrations were seen with the $5 \mathrm{mg}$ spray. There appeared to be dose proportionality between the two sublingual spray doses.

No clinically important changes in haemodynamics occurred with the spray formulation relative to the capsule. All treatments were well tolerated.

Table 1

\begin{tabular}{lccccc}
\hline & $\begin{array}{c}\mathrm{C}_{\max } \\
\text { Geometric mean }\end{array}$ & $95 \%$ CI & $\begin{array}{c}\text { AUC }(0, t) \\
\text { Geometric mean }\end{array}$ & $95 \%$ CI & $\begin{array}{c}\mathrm{t}_{\text {max }} \\
\text { Geometric mean }\end{array}$ \\
\hline B/A & 1.24 & $0.96,1.60$ & 1.06 & $0.89,1.25$ & 0.75 \\
C/A & 1.30 & $1.01,1.69$ & 1.07 & $0.90,1.26$ & 0.72 \\
C/B & 1.04 & $0.81,1.36$ & 1.01 & $0.85,1.20$ & 0.98 \\
\hline
\end{tabular}

The effect of repeated-dose activated charcoal on the pharmacokinetics of sodium valproate in healthy volunteers
A. AL-SHAREEF, D. C. BUSS, H. G. M. SHETTY, N. ALI \& P. A. ROUTLEDGE Department of Pharmacology and Therapeutics, University of Wales College of Medicine, Heath Park, Cardiff CF4 4XN and Department of Respiratory Medicine, Llandough Hospital, Cardiff

Sodium valproate may cause severe toxicity in overdose. Although early administration of charcoal may prevent absorption of the drug (Neuvonen et al., 1983), little is known of the effects of repeated dose charcoal on the elimination of sodium valproate. The pharmacokinetics of sodium valproate were studied in seven healthy volunteers after administration of the syrup ( $300 \mathrm{mg}$ ) on two occasions, one of which was followed by repeated doses of oral 
charcoal ( $20 \mathrm{~g}$ initially followed by five doses of $10 \mathrm{~g}$ ) from 4 to $32 \mathrm{~h}$ after the dose in a two way randomised crossover design. Seven subjects completed the study (one withdrew because of nausea and vomiting) and the results are shown in Table 1.
There was no significant difference in any of the pharmacokinetic variables after charcoal compared with control.

We conclude that repeated doses of activated charcoal do not appear to enhance the rate of elimination of sodium valproate in man.

Table 1

\begin{tabular}{ccccccccc}
\hline \multicolumn{3}{c}{ No charcoal } & \multicolumn{3}{c}{ Charcoal } \\
Subject & $\begin{array}{c}\mathrm{C}_{\text {max }}\left(m g l^{-1}\right) \\
\mathrm{t}_{\text {max }}\end{array}(h)$ & $\begin{array}{c}\text { AUC }(0-48) \\
\left(m g l^{-1} h\right)\end{array}$ & $\begin{array}{c}\mathrm{t}_{1 / 2} \\
(h)\end{array}$ & $\begin{array}{c}\mathrm{C}_{\text {max }} \\
\left(m g l^{-1}\right)\end{array}$ & $\begin{array}{c}\mathrm{t}_{\max } \\
(h)\end{array}$ & $\begin{array}{c}\text { AUC }(0-48) \\
\left(m g l^{-1} h\right)\end{array}$ & $\begin{array}{c}\mathrm{t}_{1 / 2} \\
(h)\end{array}$ \\
\hline 1 & 22.1 & 1 & 377.7 & 30.4 & 22.1 & 1 & 342.3 & 37.1 \\
2 & 21.1 & 1 & 338.8 & 23.1 & 24.9 & 1 & 344.8 & 24.8 \\
3 & 22.0 & 1 & 340.5 & 18.1 & 25.3 & 1 & 341.7 & 22.5 \\
4 & 18.1 & 1 & 307.0 & 13.9 & 17.5 & 1 & 288.2 & 15.7 \\
5 & 29.2 & 2 & 385.2 & 10.1 & 27.5 & 2 & 390.2 & 10.1 \\
6 & 36.3 & 1 & 635.4 & 24.6 & 27.5 & 2 & 610.0 & 22.1 \\
7 & 27.8 & 1 & 479.8 & 20.1 & 29.3 & 1 & 471.5 & 14.6 \\
Mean & 25.2 & 1.14 & 409.2 & 20.0 & 24.9 & 1.29 & 398.4 & 20.9 \\
s.d. & 6.25 & 0.38 & 113.9 & 6.81 & 3.97 & 0.49 & 109.1 & 8.8 \\
\hline
\end{tabular}

Neuvonen, P. J. et al. (1983). Eur. J. clin. Pharmac.,

24, 243.

\section{Lack of effect of propranolol on sumatriptan pharmacokinetics}

\author{
A. K. SCOTT, T. WALLEY, A. M. \\ BRECKENRIDGE, L. F. LACEY ${ }^{1} \&$ P. A. \\ FOWLER $^{1}$ \\ Department of Pharmacology and Therapeutics, \\ University of Liverpool, P.O. Box 147, Liverpool \\ L69 3BX and ${ }^{1}$ Glaxo Group Research Ltd, Ware, \\ Hertfordshire SG12 0DP
}

Sumatriptan (S) (GR43175) is a selective $5 \mathrm{HT}_{1^{-}}$ like receptor agonist which is an effective treatment for acute migraine and which may need to be administered to patients taking prophylactic (P) propranolol treatment. $\mathrm{S}$ is mainly cleared by hepatic metabolism, the major metabolite being the indole acetic acid analogue of S. Since P may inhibit oxidative metabolism it is clearly important to study whether or not it interacts with S.

Ten healthy, drug-free, male volunteers (aged 23-38 years) were studied using a doubleblind, randomised, two-way crossover design. The power of the study was $90 \%$ to detect a $20 \%$ change in $\operatorname{AUC}(\infty)$ at the $5 \%$ significance level. Approval was granted by Merseyside
Regional Ethics Committee and all volunteers gave written consent.

Each subject received S ( $300 \mathrm{mg}$ by mouth) on two occasions at least 14 days apart. Each study day was preceded by 6 days treatment with P $80 \mathrm{mg}$ twice daily, or matching placebo. On the study days, subjects attended after an overnight fast. An indwelling intravenous cannula was inserted for collection of blood samples prior to dosing and at 15 min intervals until $60 \mathrm{~min}, 30 \mathrm{~min}$ intervals until $5 \mathrm{~h}$ and at $6,8,10,12,24$ and $26 \mathrm{~h}$ post-dosing. Fluids were allowed from $2 \mathrm{~h}$ and a light lunch supplied at $4 \mathrm{~h}$ post-dosing. $\mathrm{P}$ was administered at $1 \mathrm{~h}$ before and $11 \mathrm{~h}$ after $\mathrm{S}$ dosing on the study day. No alcohol or caffeine containing drinks were permitted.

Plasma S concentrations were measured by h.p.l.c. AUC was calculated by the trapezoidal rule and the plasma rate constant by log-linear regression. $C_{\max }, \mathrm{AUC}$ and rate constant were analysed using ANOVA. $t_{\max }$ was analysed by a non parametric method (Koch).

There was no statistically significant difference between any of the derived pharmacokinetic parameter values. However, the difference in $t_{\max }$ approached significance $(P=$ 
$0.06)$ but is small in comparison with the wide inter-subject range.

$P$ did not alter any of the derived pharmacokinetic parameters of $\mathrm{S}$. Also co-administration of $P$ and $S$ was well tolerated. Thus the therapeutic dose of sumatriptan will not need to be altered in migraineurs taking prophylactic propranolol treatment.

Table 1 The results AUC(0-12 h) (mean and 95\% CI; median and range for $t_{\max }$ )

\begin{tabular}{lcccc}
\hline & $\mathrm{C}_{\max }\left(n g m l^{-1}\right)$ & $\mathrm{t}_{\max }(h)$ & $A U C(0-12 h)\left(n g m l^{-1} h\right)$ & $\mathrm{t}_{1 / 2}(h)$ \\
\hline Placebo & $126(106-149)$ & $3.0(1.0-5.0)$ & $566(470-683)$ & $1.8(1.7-2.0)$ \\
Propranolol & $120(101-143)$ & $4.5(1.0-4.5)$ & $580(481-699)$ & $1.9(1.8-2.1)$ \\
\hline
\end{tabular}

\section{Error in back-extrapolation for estimation of blood alcohol concentration}

\author{
Y. AL-LANQAWI, T. A. MORELAND, J. \\ McEWEN, F. HALLIDAY, C. J. DURNIN \& I. H. \\ STEVENSON \\ Department of Pharmacology and Clinical \\ Pharmacology, University of Dundee, Ninewells \\ Hospital and Medical School, Dundee DD1 9SY
}

Classically, alcohol (ethanol) elimination kinetics are described by a zero-order process (Widmark, 1932) and as a consequence of this a straight-line equation has been used to backextrapolate the alcohol concentration several hours prior to the actual sampling time. Apart from the validity of assuming simple zero order kinetics, a major difficulty stems from the assumption that the population average elimination rate is valid for the individual. The aim of this study was to determine alcohol kinetic parameters under controlled conditions and to investigate the validity of the back extrapolation. For comparative purposes, three slope values were used: a) the value frequently cited as a population mean, $150 \mathrm{mg} \mathrm{l}^{-1} \mathrm{~h}^{-1}$ (Walls \& Brownlie, 1985), b) the actual mean value for each group studied and c) the highest value observed in each study group.

Two groups of twelve, fasted, healthy male volunteers were given $710 \mathrm{mg} \mathrm{kg}^{-1}$ of alcohol ( $90 \% \mathrm{BP}$ ) diluted to $300 \mathrm{ml}$ with orange juice over a 5 min period. Plasma alcohol concentrations were determined at $0,0.25,0.5,0.75,1$,

Walls, H. S. \& Brownlie, A. R. (1985). Drink, drugs and driving. London: Sweet and Maxwell.

Widmark, E. M. P. (1932). Die theoretischen Grund-
$1.33,1.67,2,3,4,5,6,7,8$ and 9 h by g.l.c. The mean (range) age, weight and alcohol elimination rate of the subjects in Group I were 35 (21-51) years, 73 (64-80) kg, 196 (163-238) $\mathrm{mg} \mathrm{l}^{-1} \mathrm{~h}^{-1}$; and in Group II were 29 (19-37) years, $71(60-92) \mathrm{kg}, 176(136-238) \mathrm{mg} \mathrm{l}^{-1} \mathrm{~h}^{-1}$, respectively. The measured values at 4 and $6 \mathrm{~h}$ post-dose were used as base figures and were back extrapolated for 2 and $3 \mathrm{~h}$ in the case of the former and 3 and $4 \mathrm{~h}$ in the case of the latter. The back-extrapolation error was determined as the difference between the observed and the extrapolated values.

In the overall group of 24 subjects a mean elimination rate of $186 \mathrm{mg} \mathrm{l}^{-1} \mathrm{~h}^{-1}$ was observed; when a slope of $150 \mathrm{mg} \mathrm{l}^{-1} \mathrm{~h}^{-1}$ was used for back extrapolation a significant under-estimation of the blood alcohol concentration occurred with both time periods (mean errors of -6 to $-18 \%$ ). In contrast, the slope value of $238 \mathrm{mg}$ $\mathrm{l}^{-1} \mathrm{~h}^{-1}$ resulted in a significant over-estimation of the same concentrations (mean errors of +13 to $+24 \%$ ). When the mean slope of $186 \mathrm{mg}$ $\mathrm{l}^{-1} \mathrm{~h}^{-1}$ was used to back-extrapolate the concentration the errors were much smaller (mean errors of -3 to $+2 \%$ ). Similar findings were observed when the data were examined in each group of 12 individuals.

This study indicates that the use of mean population alcohol elimination rates can result in appreciable errors in estimation of blood alcohol concentration by the back-extrapolation procedure.

lagen und die praktische Verwendbarkeit der gerichtlich-medizinischen Alkoholbestimmung. Berlin: Urban and Schwarzenberg. 
Infusion rate as determinant in induction of anaesthesia

\section{S. REILLY, S. S. GILL \& J. E. PEACOCK} (introduced by G. T. TUCKER)

Department of Anaesthesia, University of Sheffield Medical School, Sheffield S10 2RX

The adverse effects of anaesthetic induction agents are dose related. Studies of induction of anaesthesia using a fixed dose injected at different rates have shown little difference in the incidence of adverse cardiorespiratory effects between induction rates (Gilles \& Lees, 1989; Rolly et al., 1985). We have studied the effect of rate of injection as a determinant of total dose required and of time of induction.

Following written informed consent, 120 elderly patients (mean age 73.0 s.d. 6.4 years, mean weight 69.4 s.d. $11.3 \mathrm{~kg}$ ) who presented for elective surgery were studied. They were allocated randomly to one of three groups for induction of anaesthesia. Following temazepam $20 \mathrm{mg}$ orally $1 \mathrm{~h}$ before and fentanyl $0.75 \mu \mathrm{g} \mathrm{kg}^{-1}$ i.v. $5 \mathrm{~min}$ before, anaesthesia was induced with propofol $\left(10 \mathrm{mg} \mathrm{ml}^{-1}\right)$ given at 5 , 10 or $20 \mathrm{ml} \mathrm{min}^{-1}$. Loss of verbal contact was taken as the endpoint of infusion.

The mean induction dose was 1.20 (s.e. mean

Gilles, G. W. A. \& Lees, N. W. (1989). Anaesthesia, 44, 386.

Rolly, G. et al. (1985). Br. J. Anaesth., 57, 743.
$0.04), 1.66(0.05)$ and $2.52(0.08) \mathrm{mg} \mathrm{kg}^{-1}$ for infusion at 5,10 and $20 \mathrm{ml} \mathrm{min}^{-1}$ respectively. Mean induction time was 100 (s.e. mean 4), 68 (2) and 51 (1) $\mathrm{s}$ for 5, 10 and $20 \mathrm{ml} \mathrm{min}^{-1}$. An initial correlation between both total dose and induction time with patient factors (age, weight, BMI, height and infusion rate) produced the formulae;

total dose $=71.1+5.7$ (infusion rate) +0.62 (weight) -0.82 (age) $\left(P<0.01 r^{2}=0.76\right)$. Induction time $=77.2+0.56$ (total dose $)-6.2$ (infusion rate) $\left(P<0.001, r^{2}=0.78\right)$.

A further 30 patients were studied and total dose and induction time noted. The patient details, age, weight and infusion rate were given to an independent observer who calculated dose and induction time. The extent of agreement between predicted and actual was measured by the method described by Sheiner \& Beal (1981). This demonstrated that for dose the formula had a bias of $-2.9 \mathrm{mg}(\mathrm{CI}-8.0$ : +2.2$)$ and precision of $13.9 \mathrm{mg}$ and for time of induction a bias of $-2.1 \mathrm{~s}(\mathrm{CI}-4.4:+0.2)$ and precision of $6.4 \mathrm{~s}$. Addition of the 30 patients to the initial correlation made only minor changes to the formulae. Rate of infusion appears to be an important determinant of total dose required for induction of anaesthesia.

Sheiner, L. B. \& Beal, S. L. (1981). J. Pharmacokin. Biopharm., 9, 503.

the renal effects of tyramine (which causes presynaptic release of endogenous NA) in normal man.

Eight salt replete male subjects were studied on three occasions. In addition to a conventional overhydration protocol, lithium clearance $\left(\mathrm{CL}_{\mathrm{Li}}\right)$ procedure was employed to assess proximal tubular $\mathrm{Na}^{+}$reabsorption. After an equilibration period of $1.5 \mathrm{~h}$, the following $2 \mathrm{~h}$ infusions of tyramine were given with placebo (P) control: $2 \mu \mathrm{g} \mathrm{kg}^{-1} \mathrm{~min}^{-1}, 15 \mu \mathrm{g} \mathrm{kg}^{-1} \mathrm{~min}^{-1}$. Inulin and $\mathrm{PAH}$ clearance procedure was employed for estimation of GFR and renal plasma flow (RPF) respectively. Values are shown as mean \pm s.e. mean for baseline and responses to tyramine.

Mean arterial pressure ( $\mathrm{mm} \mathrm{Hg}$ ): $87 \pm 4,85$ $\pm 4(\mathrm{P}), 88 \pm 4,88 \pm 4(2 \mu \mathrm{g}), 88 \pm 4,103 \pm$ $7^{*}(15 \mu \mathrm{g})\left({ }^{*} P<0.01\right) . R P F\left(\mathrm{ml} \mathrm{min}^{-1}\right): 542 \pm$ $47,459 \pm 43$ (P); $588 \pm 36,488 \pm 55(2 \mu \mathrm{g}), 449$ $\pm 55,543 \pm 55^{*}(15 \mu \mathrm{g})\left({ }^{*} P<0.05\right)$. Absolute et al., 1990). The current study now examines 
urinary sodium excretion $\left(\mathrm{UvNa}^{+}\right)$ $\left(\mu \mathrm{mol} \mathrm{min}{ }^{-1}\right): 96 \pm 18,67 \pm 11$ (P) $111 \pm 16$, $67 \pm 10(2 \mu \mathrm{g}) ; 83 \pm 14,119 \pm 25^{*}(15 \mu \mathrm{g})\left({ }^{*} P\right.$ $<0.01) . C L_{L i}\left(\mathrm{ml} \mathrm{min}^{-1}\right): 23 \pm 4,17 \pm 4(\mathrm{P})$; $22 \pm 5,18 \pm 4(2 \mu \mathrm{g}) ; 22 \pm 4,21 \pm 4(15 \mu \mathrm{g})$. There was no significant change noted in the fractional distal $\mathrm{Na}^{+}$reabsorption. Plasma noradrenaline $\left(\mathrm{ng} \mathrm{ml}^{-1}\right): 0.7 \pm 0.2,0.8 \pm 0.2$ (P), $0.6 \pm 0.2,1.1 \pm 0.3^{*}(2 \mu \mathrm{g}) ; 0.8 \pm 0.2,1.4$ $\pm 0.35^{* *}(15 \mu \mathrm{g})\left({ }^{*} P<0.01,{ }^{* *} P<0.001\right)$. Plasma renin activity $\left(\mathrm{ng} \mathrm{ml} \mathrm{m}^{-1} h^{-1}\right): 2.7 \pm 0.6$, $2.5 \pm 0.6(\mathrm{P}), 1.8 \pm 0.4,1.4 \pm 0.5(2 \mu \mathrm{g}), 1.7$ $\pm 0.9,1.4 \pm 1.0(15 \mu \mathrm{g})$. Angiotensin II level $\left(\mathrm{pg} \mathrm{ml}^{-1}\right): 27 \pm 4,27 \pm 5(\mathrm{P}) ; 32 \pm 5,28 \pm 2$ $(2 \mu \mathrm{g}) ; 34 \pm 6,23 \pm 3^{*}(15 \mu \mathrm{g})\left({ }^{*} P<0.01\right)$. Plasma aldosterone ( $\left.\mathrm{pg} \mathrm{ml}^{-1}\right): 265 \pm 36,295$ \pm 44 (P); $237 \pm 27,273 \pm 38(2 \mu \mathrm{g}) ; 226 \pm 28$,

Lang, C. C. et al. (1990). Br. J. clin. Pharmac., 30, $335 \mathrm{P}$.
$191 \pm 26^{*}(P<0.05)$.

In summary, we have shown that a pressor dose of tyramine resulted in an increase in urinary sodium output in man. These changes are accompanied by an increase in renal plasma flow with consequent suppression of the renin angiotensin aldosterone system. Taken in conjunction with our previous findings with circulating noradrenaline, it would appear that circulating noradrenaline and neuronally released noradrenaline have opposite effects on renal sodium handling in man. Sympathetic overactivity, a feature of $\mathrm{CHF}$ may therefore have unpredictable effects on urinary sodium output in man, depending on the balance between circulating and neuronally release NA.

\section{Renal effects of circulating noradrenaline in man: dose-response studies}

C. C. LANG*, A. R. RAHMAN, W. J. K. COUTIE, D. J. K. BALFOUR \& A. D. STRUTHERS

Department of Clinical Pharmacology, Ninewells Hospital \& Medical School, Dundee DD1 9SY, Scotland.

In recent years, accumulative evidence suggests that the renal sympathetic nervous system (SNS) is an important regulator of sodium excretion. SNS activity consists of two components-localised synaptic noradrenaline (NA) release and spillover NA into the general circulation. However, the renal effects of the latter component i.e. circulating NA have received little attention in man. We have therefore examined the dose response relationship between circulating noradrenaline and renal function in man.

Nine subjects were studied on five occasions. In addition to a conventional overhydration protocol (Roberts \& Daneshmend, 1981), lithium clearance $\left(\mathrm{CL}_{\mathrm{Li}}\right)$ procedure was employed to assess proximal tubular $\mathrm{Na}^{+}$ reabsorption. After an equilibration period of $1.5 \mathrm{~h}$, the following $2 \mathrm{~h}$ infusions of NA were given with placebo (P) control: $15 \mathrm{ng} \mathrm{kg}-1$ $\min ^{-1}, 25 \mathrm{ng} \mathrm{kg}^{-1} \mathrm{~min}^{-1}, 50 \mathrm{ng} \mathrm{kg}^{-1} \mathrm{~min}^{-1}, 75$ $\mathrm{ng} \mathrm{kg} \mathrm{min}^{-1}$. Inulin and PAH clearance procedure was employed for estimation of GFR and RPF respectively. Values are shown as mean \pm s.e. mean for baseline and responses to NA.
Mean arterial pressure ( $\mathrm{mm} \mathrm{Hg}$ ): $91 \pm 3,94$ \pm 3 (P); $92 \pm 3,93 \pm 4$ (NA 15 ng); $91 \pm 3,94$ \pm 3 (NA $25 \mathrm{ng}$ ); $89 \pm 3,96 \pm 4$ *(NA $50 \mathrm{ng}$ ); $90 \pm 4,100 \pm 4 * *$ (NA $75 \mathrm{ng})\left[{ }^{*} P<0.05, * * P\right.$ $<0.01]$. RPF $\left(\mathrm{ml} \mathrm{min}^{-1}\right): 512 \pm 30,517 \pm 35$ (P); $566 \pm 32,511 \pm 28$ (NA $15 \mathrm{ng}$ ); $535 \pm 30$, $490 \pm 27$ (NA $25 \mathrm{ng}$ ); $499 \pm 40,421 \pm 30^{*}$ (NA $50 \mathrm{ng}$ ); $563 \pm 36,408 \pm 40^{* *}$ (NA $75 \mathrm{ng} \mathrm{kg}^{-1}$ $\left.\min ^{-1}\right)\left[{ }^{*} P<0.05,{ }^{* *} P<0.05\right]$. Absolute $\mathrm{Na}^{+}$


$134 \pm 12(\mathrm{P}) ; 154 \pm 24,147 \pm 20$ (15 ng); 144 $\pm 14,118 \pm 8(25 \mathrm{ng}) 144 \pm 12,110 \pm 14^{*}(50$ ng) $142 \pm 15,101 \pm 13^{* *}$ (75 ng) $\left[{ }^{*} P<0.05\right.$, $* * P<0.05]$. Lithium clearance $\left(\mathrm{ml} \mathrm{min}^{-1}\right): 33$ $\pm 2,33 \pm 2(\mathrm{P}) ; 33 \pm 2,33 \pm 2(15 \mathrm{ng}) ; 31 \pm$ $3,28 \pm 2(25 \mathrm{ng}) ; 36 \pm 6,30 \pm 5(50 \mathrm{ng}) ; 34 \pm$ $6,27 \pm 4^{*}(75 \mathrm{ng})\left({ }^{*} P<0.05\right)$. No significant change was noted in the GFR and fractional distal reabsorption of $\mathrm{Na}^{+}\left(\mathrm{CH}_{2} \mathrm{O} / \mathrm{CNa}^{+} \mathrm{xCH}_{2} \mathrm{O}\right)$.

Plasma noradrenaline ( $\mathrm{ng} \mathrm{ml}$ ): $0.7 \pm 0.2$, $0.8 \pm 0.2(\mathrm{P}) ; 0.6 \pm 0.1,0.8 \pm 0.1$ (15 ng); 0.6 $\pm 0.2,1.1 \pm 0.3^{*}(25 \mathrm{ng}) ; 0.6 \pm 0.2,1.1 \pm 0.3^{*}$ $(50 \mathrm{ng}) ; 0.8 \pm 0.2,1.3 \pm 0.3^{*}\left(75 \mathrm{ng} \mathrm{kg}^{-1} \mathrm{~min}^{-1}\right)$ $\left({ }^{*} P<0.01\right)$. At the top NA dose $(75 \mathrm{ng})$, there was evidence of a modest activation of the renin angiotensin aldosterone system. Plasma angiotensin II ( $\left.\mathrm{pg} \mathrm{ml}^{-1}\right): 57 \pm 7,58 \pm 8(\mathrm{P})$; $56 \pm 7,74 \pm 8^{*}(75 \mathrm{ng})[* P<0.05]$. Plasma aldosterone $\left(\mathrm{pg} \mathrm{ml}^{-1}\right): 245 \pm 34,267 \pm 21(\mathrm{P})$, $261 \pm 50,353 \pm 58 *(75 \mathrm{ng})\left[{ }^{*} P<0.05\right]$. Plasma

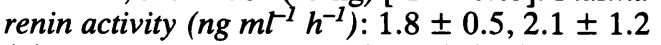
(P); $1.7 \pm 1.0,2.2 \pm 1.1$ (75 ng) (NS).

In summary we have shown that increments in circulating noradrenaline have an antinatriuretic action in man; actions partly ex- 
plained by a reduction in renal plasma flow as well as enhancement of proximal tubular reabsorption and the activation of the renin angiotensin aldosterone system. Circulating

Roberts C. J. \& Daneshmend T. K. (1981). Br. J. clin. Pharmac., 12, 465. noradrenaline, per se, may therefore influence renal function in certain pathological states such as chronic heart failure which is associated with high plasma levels of this hormone.

\section{Redistribution of blood flow by angiotensin II in man: a dose-response study}

\section{J. G. MOTWANI \& A. D. STRUTHERS}

Department of Clinical Pharmacology, Ninewells Hospital and Medical School, Dundee DD1 9SY, Scotland

Angiotensin II is recognised as a potent vasoconstrictor through its ability to elevate systemic blood pressure. However, this pressor effect may be a crude summation of different regional effects on different blood compartments. The purpose of the present study was to investigate in normal man the effect of infusion of different doses of angiotensin II on a number of regional haemodynamic parameters.

Eight young adult male volunteers were studied on four occasions each at least 3 days apart. On each day, after an 80 min equilibration period, one of the following infusions was administered over $2 \mathrm{~h}$ in randomised single blind fashion: angiotensin II 0, 1, 3 and $10 \mathrm{ng}$ $\mathrm{kg}^{-1} \mathrm{~min}^{-1}$. Every 30 min cardiac output (CO), left ventricular ejection fraction (LVEF), stroke volume (SV) and end diastolic volume (LVEDV) were determined by thoracic impedance plethysmography and calf blood flow (CBF) and calf venous capacitance (CVC) by venous occlusion plethysmography. Total peripheral resistance (TPR) was derived using an established formula.

We found a pronounced dose-related negative inotropic effect of angiotensin II in vivo which is in contrast to the positive inotropic effect previously noted in the isolated myocardial preparation (Baker \& Khosla, 1986). Our finding may relate to the recent observation of Neyses \& Vetter (1989) that angiotensin II impairs relaxation of isolated myocardial cells thus reducing ventricular compliance. In accordance with this was our finding of a concomitant reduction in left ventricular end-diastolic volume. Another possible explanation for the reductions in end diastolic volume and stroke volume is diminished venous return secondary to the increased peripheral venous pooling noted in this study with the higher doses ( 3 and $10 \mathrm{ng} \mathrm{kg}^{-1} \mathrm{~min}^{-1}$ ) of angiotensin II.

Table 1 The results (change from baseline, mean \pm s.e. mean)

\begin{tabular}{|c|c|c|c|c|c|}
\hline \multirow[t]{2}{*}{ Parameter } & \multicolumn{4}{|c|}{ Angiotensin II dose (ng $\mathrm{kg}^{-1} \mathrm{~min}^{-1}$ ) } & \multirow{2}{*}{$\begin{array}{c}\text { Significance } \\
\text { level } \\
\text { (P) }\end{array}$} \\
\hline & 0 (Placebo) & 1 & 3 & 10 & \\
\hline Systolic BP (mm & $1 \pm 0.6$ & $6 \pm 0.6^{*}$ & $13 \pm 0.6^{*}$ & $18 \pm 0.6^{*}$ & $<0.00005$ \\
\hline Diastolic BP (mm Hg) & $2 \pm 0.6$ & $6 \pm 0.6^{*}$ & $13 \pm 0.6^{*}$ & $22 \pm 0.6^{*}$ & $<0.00005$ \\
\hline TPR (dyn s $\mathrm{cm}^{-5}$ ) & $102 \pm 30$ & $230 \pm 30 *$ & $327 \pm 30^{*}$ & $529 \pm 30^{*}$ & $<0.00005$ \\
\hline $\mathrm{CO}\left(1 \mathrm{~min}^{-1}\right)$ & $-0.7 \pm 0.1$ & $-1.3 \pm 0.1$ & $-1.5 \pm 0.1^{*}$ & $-1.9 \pm 0.1^{*}$ & $<0.00005$ \\
\hline SV (ml) & $-5 \pm 2$ & $-14 \pm 2 *$ & $-15 \pm 2 *$ & $-17 \pm 2^{*}$ & $<0.00005$ \\
\hline LVEDV (ml) & $-7 \pm 2$ & $-15 \pm 2$ & $-17 \pm 2 *$ & $-18 \pm 2^{*}$ & $<0.005$ \\
\hline $\mathrm{CBF}\left(\mathrm{ml}^{-1} \mathrm{~min}^{-1} 100 \mathrm{~g}^{-1}\right)$ & $-0.4 \pm 0.1$ & $-0.6 \pm 0.1$ & $-0.2 \pm 0.1$ & $0.1 \pm 0.1^{*}$ & $<0.0005$ \\
\hline $\operatorname{CVC}\left(\mathrm{ml}^{-1} 100 \mathrm{~g}^{-1}\right.$ at $\left.60 \mathrm{~mm} \mathrm{Hg}\right)$ & $-0.3 \pm 0.1$ & $-0.3 \pm 0.1$ & $0.3 \pm 0.1^{*}$ & $0.4 \pm 0.1^{*}$ & $<0.00005$ \\
\hline
\end{tabular}

* indicates significantly different from placebo, repeated measures analysis of variance.

Baker, K. M. \& Khosla, M. C. (1986). J. Pharmac. exp. Ther., 239, 790.
Neyses, L. \& Vetter, H. (1989). J. Hypertension, Suppl. 6, S104. 


\section{Attitudes of physicians towards the treatment of elevated serum cholesterol}

G. McDERMID, C. C. LANG, J. F. DORAN ${ }^{1}$ \& A. D. STRUTHERS

Department of Clinical Pharmacology and

${ }^{1}$ Biochemical Medicine, Ninewells Hospital and

Medical School, Dundee DD1 9SY, Scotland

Coronary heart disease (CHD) is a major cause of morbidity and mortality in the western industrialised world with the UK rate being amongst the highest. It is now well established that a raised level of serum cholesterol in particular LDL cholesterol significantly contributes to an individual's risk of CHD. As a result, policy statements have emerged in recent years from North America, Europe and the UK with recommendations on assessment of CHD risk factors, screening and the level of total serum cholesterol at which intervention should be initiated. However, these policy statements raise complex practical issues since, for example, in Scotland, 35\% of the population are above the threshold for treatment (TunstallPedoe et al., 1989). The successful implementation of any health policy is dependent on the motivation and attitudes of the physicians who see the patients. We have therefore conducted a postal questionnaire survey to investigate the attitudes of both general practitioners and hospital doctors to the screening and treatment of hypercholesterolaemia.

The questionnaire, of multiple choice type consisting of 10 stem items, was mailed to 457
Tayside physicians (328 general practitioners, 129 post-registration hospital doctors in medical specialities) in a single batch in April 1989. The results were analysed using the chi-squared test to assess differences between groups. A $P$ value of $<0.05$ was considered significant.

Replies were received from $206(63 \%)$ general practitioners, 94 (74\%) hospital doctors. While hypertension, smoking, diabetes mellitus and elevated total serum cholesterol were recognised as major risk factors for $\mathrm{CHD}$, a significant number of respondents considered elevated serum triglyceride to be less important $(P<0.01)$. Although both physician groups would start dietary management at similar serum cholesterol levels, hospital doctors were more likely to use dietetic services. The two groups had a similar threshold for the addition of drug therapy. Whilst a bile acid sequestrant was the favoured first choice as a cholesterol lowering agent, a wide variety of other drugs were also chosen. The screening of high risk patients was preferred to whole population and opportunistic screening when identifying hypercholesterolaemic individuals.

Clearly physicians are not in favour of widespread screening and are only in favour of screening patients who already have overt disease. This attitude may understandably be due to the extra workload which widespread screening would impose on them. If widespread screening is decided upon, then extra resources in terms of personnel would probably need to be allocated to implement such a policy.

Tunstall-Pedoe, H. et al. (1989). Lancet, i, 540.

\section{Vasodepressor syncope and catecholamine response}

H. BAUMGARTNER*, H. HÖRTNAGL, G. LÜCKE, J. STRIESSNIG, C. J. WIEDERMANN \& G. HOCHLEITNER (introduced by $H$. GLOSSMANN)

University of Innsbruck, Institut für Biochemische Pharmakologie, Peter Mayrstrasse 1, A-6020 Austria

In this study we investigated the catecholamine (CAT), heart rate and blood pressure response of healthy young men to orthostatic challenge; after $30 \mathrm{~min}$ of supine rest (REST) they stood quietly for $10 \mathrm{~min}$. Forearm venous plasma catecholamines were analysed radioenzymatically (Baumgartner et al., 1985). Nine subjects
(NORMALS) were able to tolerate the test, while four developed vasodepressor syncope (VDS). The CAT response to VDS was remarkable (Table 1): the noradrenaline (NA) increase did not exceed the orthostatic NA rise of NORMALS, despite attack associated hypotension. In contrast to NORMALS, a substantial rise of adrenaline (A) was present after fainting. This dissociation of the sympathoadrenomedullary reaction is clearly reflected in the NA/A ratio: the postfaint NA/A ratio is smaller or close to the supine ratio; the orthostatic NA/A ratio in NORMALS increases to nearly twice the supine ratio.

This blunted NA response and an exaggerated A reaction in postfaint venous forearm blood samples appears to resemble a characteristic 
response of VDS. We view this CAT change as an expression of two key elements of the fainting reaction (low NA: vasodepression; high A: a state of emergency) and we suggest that this response can potentially be useful as a biochemical marker for the fainting reaction; support comes in part from a rechallenge experiment with two of the fainters. Early detection of orthostatic vulnerability by biochemical means would be less drastic than currently used provocation methods (Almquist et al., 1989; Fitzpatrick \& Sutton, 1889) for the diagnosis of unexplained syncope; moreover, this approach could probably be useful for the study of various factors, including drugs, that influence orthostatic tolerance.

This study was supported by the Dr Legerlotz Stiftung.

Table 1

\begin{tabular}{|c|c|c|c|c|c|}
\hline & \multirow{2}{*}{$\begin{array}{c}\text { Normals } \\
(\mathrm{n}=9)\end{array}$} & \multicolumn{4}{|c|}{$V D S$-subjects } \\
\hline & & $V D S-1$ & $V D S-2$ & $V D S-3$ & $V D S-4$ \\
\hline & Rest & \multicolumn{4}{|c|}{ Rest } \\
\hline $\begin{array}{l}\text { NA }\left(\mathrm{pg} \mathrm{ml}^{-1}\right) \\
\text { A (pg ml } \\
\text { NA/A ratio }\end{array}$ & $\begin{array}{l}112-252 \text { (range) } \\
18-68 \\
5.7(4.5)\end{array}$ & $\begin{array}{r}354 \\
90\end{array}$ & $\begin{array}{r}247 \\
33 \\
7.3\end{array}$ & $\begin{array}{r}170 \\
25 \\
(7.2)^{2}\end{array}$ & $\begin{array}{r}189 \\
17\end{array}$ \\
\hline & Standing & \multicolumn{4}{|c|}{ Syncopal } \\
\hline $\begin{array}{l}\text { NA }\left(\mathrm{pg} \mathrm{ml}^{-1}\right) \\
\text { A (pg ml } \\
\text { NA/A ratio }\end{array}$ & $\begin{array}{l}183-512^{* *} \\
18-100 \\
8.8(9.3)\end{array}$ & $\begin{array}{l}459 \\
163\end{array}$ & $\begin{array}{r}195 \\
122 \\
3.1\end{array}$ & $\begin{array}{r}351 \\
51 \\
(2.2)^{2}\end{array}$ & $\begin{array}{l}275 \\
259\end{array}$ \\
\hline
\end{tabular}

VDS-1 to VDS-4 refers to individual subjects.

NA/A ratio: mean (median).

Different from NORMALS: $*$ U-test: $P<0.05$; different from REST:

** Wilcoxon-test: $P<0.01$.

Almquist, A. et al. (1989). New Engl. J. Med., 320, 346.

Baumgartner, H. et al. (1985). Naunyn-Schmiede- berg's Arch. Pharmac., 328, 461.

Fitzpatrick, A. \& Sutton, R. (1989). Lancet, i, 658.

\section{Morning vs evening dosing of sustained-release verapamil in mild to moderate hypertension}

\section{POTTER, I. DEWS, T. PULLAN, L. WIGHT \& M. VANDENBURG}

MCRC Ltd, 1 Mildmay Road, Romford, Essex RM7 7DA

Three hundred and thirty-seven patients with seated diastolic blood pressure of $95-115 \mathrm{~mm} \mathrm{Hg}$ were studied in an open, parallel-group, multicentre general practice comparison of $08.00 \mathrm{~h}$ vs $20.00 \mathrm{~h}$ dosing of sustained-release verapamil (Univer ${ }^{\circledR}$, Rorer). All patients were aged 40 years or more, had no significant concomitant disease and were receiving no concomitant antihypertensive medication.

A 4-week single-blind placebo run-in was followed by randomised morning or evening dosing with verapamil SR $120 \mathrm{mg}$. Blood pressure was reassessed after 2, 6 and 10 weeks with an option to increase the dose to $240 \mathrm{mg}$ daily if control criteria (seated diastolic pressure $\leqslant 90 \mathrm{~mm} \mathrm{Hg}$ or a fall of $\geqslant 10 \mathrm{~mm} \mathrm{Hg}$ to a value $\leqslant 100 \mathrm{~mm} \mathrm{Hg}$ ) were not met. Two hundred and forty-seven patients completed the study ( 31 were not randomised, 46 were protocol violators, and 13 others withdrew).

Evaluable efficacy data were obtained from 120 morning-dosing patients and 127 eveningdosing patients. Sub-group analysis was performed on patients $<65$ years $v s 65$ years and over.

Twenty-two morning-dosing patients $(15 \%)$ and 27 evening-dosing patients $(17 \%)$ reported adverse events. The symptoms reported by more than $1 \%$ of patients were peripheral 
oedema (morning 6, evening 2), dizziness (morning 1, evening 5), headache (morning 4, evening 2) and fatigue (morning 0 , evening 3 ).

These results confirm the efficacy of verapamil in mild to moderate hypertension and show it to extend to both young and elderly patients. There were no important differences in efficacy or side effects between morning and evening dosing.

Table 1 Mean (s.e. mean) results

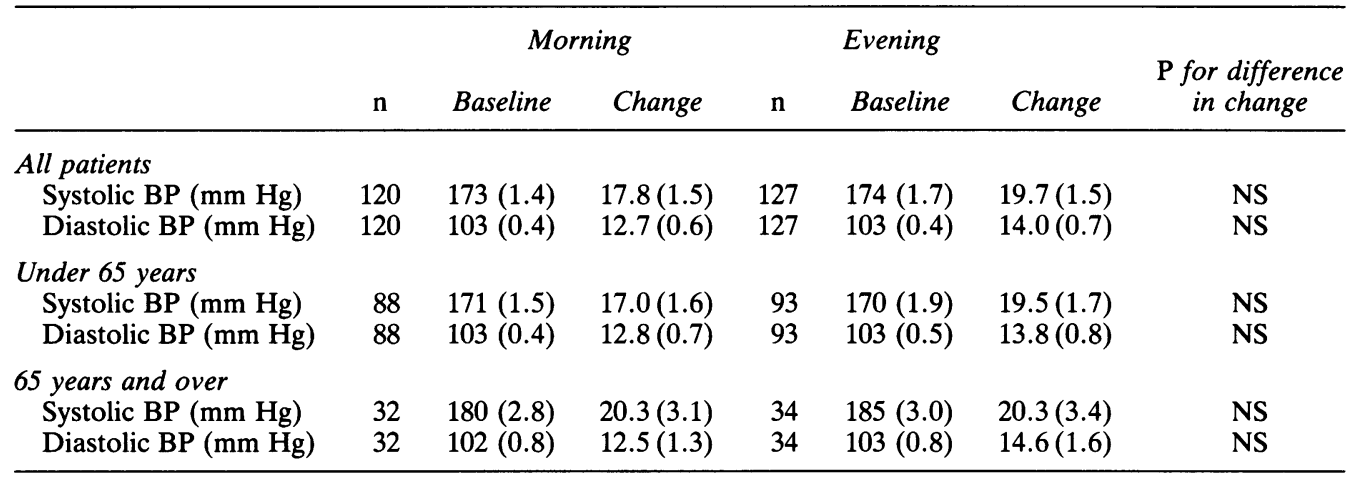

\section{A double-blind general practice based comparative study of sustained release verapamil with atenolol in patients with mild to moderate hypertension}

\section{WIGHT, M. VANDENBURG, C. POTTER \& T. PULLAN \\ MCRC Ltd, 1 Mildmay Road, Romford, Essex RM7 7DA}

A study was conducted in general practices throughout the U.K. to compare the efficacy and tolerability of sustained release verapamil (Univer ${ }^{\circledR}$ Rorer) with the established $\beta$-adrenoceptor blocker atenolol in the treatment of mild to moderate hypertension.

Male and female patients requiring treatment for mild to moderate essential hypertension aged 40 years and over were recruited onto a double-blind placebo run-in study. Patients initially entered a 4 week single-blind placebo phase and those with a seated diastolic blood pressure (Korotkoff $\mathrm{V}$ ) of $95-115 \mathrm{~mm} \mathrm{Hg}$ at the end of this time were randomised in a 2:1 ratio to receive either verapamil $120 \mathrm{mg}$ once daily or atenolol $50 \mathrm{mg}$ once daily for a further 10 weeks. Blood pressure, heart rate, concomitant medication/conditions and adverse events were recorded throughout the study at specific time points; entry to the study, 2 and 4 weeks during placebo and 2, 6 and 10 weeks after the start of active treatment. Each treatment dose could be increased to verapamil $240 \mathrm{mg}$ or $100 \mathrm{mg}$ atenolol if blood pressure was uncontrolled 2 or 6 weeks after the start of active treatment. At the end of the study each investigator assessed the therapy suitability and patients recorded their satisfaction with the therapy.

A total of 90 patients entered the study, 62 randomised to receive verapamil and 28 to receive atenolol. Of these, 51 verapamil and 25 atenolol patients were included in the efficacy analysis. Baseline placebo demographic, blood pressure and heart rate data were not found to differ significantly between the two groups. Both treatment groups' blood pressure decreased significantly during active treatment (verapamil $168.79 \pm 2.11-150.56 \pm 2.17$ $(\mathrm{mm} \mathrm{Hg})$ systolic, $103.86 \pm 0.86-90.39 \pm 1.33$ $(\mathrm{mm} \mathrm{Hg})$ diastolic, atenolol $167.43 \pm 2.83-$ $149.91 \pm 2.69(\mathrm{~mm} \mathrm{Hg})$ systolic, $103.97 \pm 1.0$ $90.44 \pm 1.82(\mathrm{~mm} \mathrm{Hg})$ diastolic, $P<0.001$ ). No significant difference was found between verapamil and atenolol treatment groups in the change in average seated blood pressure from the start of active treatment to any further visit. A small but significant decrease in mean seated heart rate from the start of active treatment to each further visit occurred for the verapamil group $(P<0.002), 76.18 \pm 0.99$ mean beats $\min ^{-1}$ at start, $73.98 \pm 1.01$ at 2 weeks active, $72.59 \pm 0.97$ at 6 weeks, 71.69 
\pm 0.95 at 10 weeks active, but only for the change from start to final visit for the atenolol group $(P=0.045), 75.60 \pm 1.61$ at start, 73.08 \pm 1.76 at 2 weeks active, $72.64 \pm 1.81$ at 6 weeks, $72.00 \pm 1.52$ at 10 weeks active. The investigators' assessment of therapy suitability was not found to differ significantly between the two groups. Neither was a statistical difference found in patient satisfaction. Ten patients reported adverse events none of which was severe. Four $(7.4 \%)$ of patients were receiving verapamil, four $(16 \%)$ receiving atenolol and two patients receiving placebo. Twelve events in total were reported by patients on verapamil and six events by patients receiving atenolol.

In conclusion the sustained release verapamil, Univer $^{\circledR}$, Rorer, appears to be equally as efficacious as atenolol and although in this study less patients experienced adverse events there were insufficient numbers to show a statistical difference.

\section{Sustained release verapamil in chronic stable angina pectoris: a multicentre randomised double-blind crossover design trial vs placebo}

M. VANDENBURG ${ }^{1}$, I. DEWS ${ }^{1}$, J. GIBBS $^{4}$, W. HENDRY $^{3}$, P. ROBINSON ${ }^{2}$ \& J. STEPHENS ${ }^{2}$

${ }^{1}$ MCRC Ltd, Lewis House, Mildmay Road, Romford, ${ }^{2}$ Oldchurch, ${ }^{3}$ Amersham and ${ }^{4}$ National Heart Hospitals

A comparison was made of the anti-anginal efficacy of a sustained release formulation of verapamil, Securon SR (SSR) given twice daily, $v s$ placebo, in a randomized, double-blind, crossover clinical trial. Patients commenced with a run-in week on single-blind placebo, during which no treatment other than sublingual GTN was authorised. Thereafter, the doubleblind treatment phase consisted of 2 weeks' therapy on each regime. Following the doubleblind study, patients continued on open-label active treatment for a further 3 months. This part of the study was designed to assess the continued anti-anginal efficacy after chronic treatment with sustained release verapamil.

Anti-anginal efficacy of treatment was assessed by treadmill testing according to the
Bruce protocol, approximately $12 \mathrm{~h}$ following the last dose of medication at the end of each double-blind treatment phase, and by a further exercise ECG test on completion of 3 months' open treatment. A diary card enabled patients' recording of the frequency and severity of angina pain occurring during the study period, and the numbers of GTN tablets consumed. The exercise test ECGs were interpreted by the investigator and also by an external, independent expert, who was blind to the patients' medication. Tolerability was assessed at each clinic visit, and biochemistry and haematology safety tests were performed at baseline and at the end of the study.

Patients were selected for entry to randomised therapy only if their exercising ECG tests revealed a minimum of $1 \mathrm{~mm}$ ST segment depression at baseline. Fourteen male and three female patients (mean age 62 years, s.d. 6) commenced, of whom 15 completed the doubleblind phase and 14 completed the 3 month follow-up period. Two withdrawals (from active therapy) were for severe constipation and because of poor compliance; a further patient was withdrawn during the open treatment phase following swelling of the feet and ankles.

The results clearly demonstrated the efficacy

Table 1 The result of the study after 2 weeks (mean \pm s.d.)

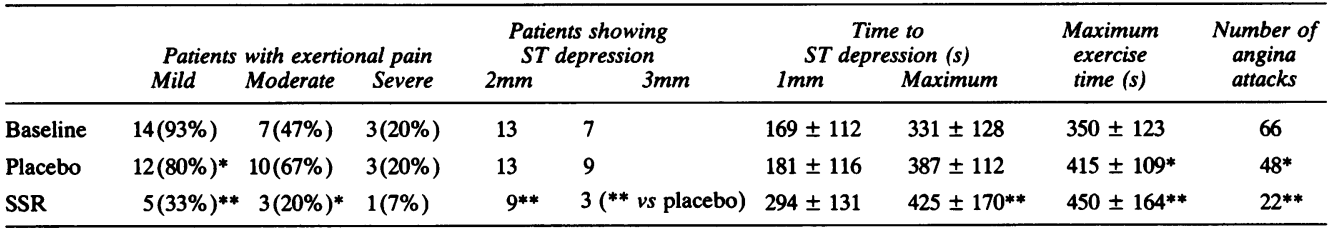

Statistically significant differences from baseline ${ }^{*} P \leq 0.05,{ }^{*} P \leq 0.01$. 
of SSR over placebo after only 2 weeks, maintained after 3 months' follow-up treatment.

There was no significant difference between end-of-active (double-blind phase) and after 3 months open label treatment on SSR for the following criteria: time to ST depression of 1 $\mathrm{mm}, 2 \mathrm{~mm}$ or $3 \mathrm{~mm}$; maximum ST segment depression and total exercise time. All of these variables were significantly improved over baseline, or over placebo treatment.

\section{Acute effects of cicletanine in angina pectoris}

\author{
D. L. MURDOCH, E. HENDERSON ${ }^{1}$, H. J. \\ DARGIE $^{1}$ \& G. T. McINNES \\ University Department of Medicine and \\ Therapeutics, Department of Cardiology, Western \\ Infirmary, Glasgow G11 6NT
}

Cicletanine is a furopyridine derivative under evaluation as an antihypertensive agent. An incidental finding in some clinical studies has been a tendency to improvement in angina frequency. The aim of this study was to investigate the potential anti-anginal action of cicletanine. Sixteen patients (mean age 40 years, 10 males) with symptoms of angina pectoris $(\geq 5$ attacks per week) and a positive exercise tolerance test (Bruce protocol) entered a doubleblind, randomised, balanced, crossover comparison of cicletanine $50 \mathrm{mg}$ and placebo each at single doses. Prophylactic anti-anginal agents were discontinued prior to the study but nitrates for symptomatic relief were un- restricted. On two study days separated by at least 1 week, patients underwent an exercise tolerance test (modified Bruce protocol) $2 \mathrm{~h}$ after drug administration and $24 \mathrm{~h}$ ambulatory ECG monitoring; heart rate and BP were recorded at intervals for $24 \mathrm{~h}$.

There were no significant changes in heart rate or BP but significantly fewer episodes of ST depression were recorded during the $24 \mathrm{~h}$ following cicletanine. There were trends in favour of cicletanine for exercise duration, mean changes $+0.49 \mathrm{~min}(95 \% \mathrm{CI}-0.40 \mathrm{~min}$, $+1.38 \mathrm{~min}$ ) and time to $1 \mathrm{~mm} \mathrm{ST}$ depression, mean change $+0.06 \mathrm{~min}(95 \% \mathrm{CI}-1.07 \mathrm{~min}$, $+1.19 \mathrm{~min}$ ). These findings offer some support for an anti-anginal action of cicletanine. Although confidence intervals for the beneficial effects were wide, an improvement in exercise tolerance of about $10-15 \%$ cannot be excluded. Such a change is comparable with that after some calcium antagonists (Low et al., 1981; Moskowitz et al., 1979). Further longer-term studies of cicletanine in angina may be warranted.

Table 1 Mean (s.e. mean) results in 16 patients with angina

\begin{tabular}{lccr}
\hline & Placebo & Cicletanine & P value \\
\hline Heart rate at $2 \mathrm{~h}\left({\left.\text { beats } \mathrm{min}^{-1}\right)}\right)$ & $66.4(2.0)$ & $66.2(2.8)$ & 0.37 \\
Systolic BP at 2 h (mm Hg) & $132.7(4.2)$ & $137.0(4.3)$ & 1.00 \\
Diastolic BP at 2 h (mm Hg) & $77.5(2.7)$ & $82.8(2.8)$ & 0.32 \\
Exercise duration (min) & $10.96(0.62)$ & $11.45(0.70)$ & 0.37 \\
Time to 1 mm ST depression (min) & $8.83(0.91)$ & $8.89(1.04)$ & 0.87 \\
Episodes of ST depression in 24 h & $2.00(0.58)$ & $0.93(0.23)$ & $<0.05$ \\
\hline
\end{tabular}

Low, R. I. et al. (1981). Am. Heart J., 101, 713.
Moskowitz, R. M. et al. (1979). Am. J. Cardiol., 44, 811. 


\section{Differences of haemodynamic effects of nitrendipine and felodipine in patients with congestive heart failure}

\section{A. HALABI, M. LINDE \& W. KIRCH \\ I. Medizinische Klinik, Christian-Albrechts- Universität, Schittenhelmstrasse 12, D-2300 Kiel, Federal Republic Germany}

Felodipine and nitrendipine are calcium antagonists of the dihydropyridine type. In previous studies with another dihydropyridine, nisoldipine, the cardiovascular effects of this calcium antagonist could be shown to have a duration of action of about $6 \mathrm{~h}$ in patients with congestive heart failure (Linde et al., 1989). Thus the aim of the present study was to compare the efficacy and duration of action of nitrendipine with that of felodipine in patients with cardiac insufficiency.

In a randomized placebo-controlled doubleblind crossover study 16 patients with congestive heart failure (NYHA II, 12 male, 4 female, $60.0 \pm 6.2$ years, $72.2 \pm 11.7 \mathrm{~kg}$, mean \pm s.d.) were treated on three different occasions (day $1,5,9$ ) with placebo $10 \mathrm{mg}$ felodipine in extended release formulation and $20 \mathrm{mg}$ nitrendipine as single oral dose. Before, 2, 6 and $24 \mathrm{~h}$ after administration mechano-, impedance cardiographic and occlusion plethysmographic parameters were determined. Stroke volume $(\Delta \mathrm{V})$ and Heather-Index $(\mathrm{HI})$ were significantly increased on nitrendipine and felodipine in impedance cardiography $(P<0.05) .2$ and $6 \mathrm{~h}$ after dosing these effects were more pronounced after administration of felodipine than nitrendipine. 12 and $24 \mathrm{~h}$ after felodipine the HeatherIndex was $14.5 \pm 6.0$ and $13.3 \pm 5.7 \Omega \mathrm{s}^{-2}$ respectively, whereas the baseline value was 12.8 and $5.2 \Omega \mathrm{s}^{-2}$. On nitrendipine baseline value of the Heather-Index was $12.7 \pm$ $4.9 \Omega \mathrm{s}^{-2}$ and it was $12.9 \pm 4.8 \Omega \mathrm{s}^{-2}$ and $12.8 \pm 4.6 \Omega \mathrm{s}^{-2} 12$ and $24 \mathrm{~h}$ after nitrendipine dosing. In mechano-cardiography left ventricular ejection time (LVET) was prolonged for 6 $\mathrm{h}$ following nitrendipine and felodipine administration $(P<0.05)$. The preejection period (PEP) was lowered on both calcium antagonists compared with placebo and baseline values $(P<0.05)$. The results of the PEP/LVET ratio behaved analogously to PEP. In occlusion plethysmography arterial blood flow was increased on felodipine and nitrendipine, and this effect lasted for $24 \mathrm{~h}$ on felodipine treatment.

In conclusion, results of the present study indicate that the haemodynamic effects of felodipine were more pronounced and of longer duration of action than those of nitrendipine.

Linde, M. et al. (1989). Z. Kardiol., 78, 181.

\section{DEMONSTRATION}

\section{1-2-3-4. One step beyond Lotus 1-2-3 for storing, tabulating and summarising pharmacokinetic data}

\section{G. D. OGG \& I. H. STEVENSON}

Department of Pharmacology and Clinical Pharmacology, University of Dundee, Ninewells Hospital, Dundee DD1 9SY

In order to store and summarise large volumes of plasma concentration-time data the obvious choice would be to enter the data into a large worksheet. This is the most popular route as tables and graphs are easily produced, but is very unwieldy due to the large number of cells occupied. The easiest solution to the problem is to produce one worksheet for each data set then combine them using '/File Combine'. Again however this produces an enormous worksheet.
The answer to all these problems comes in a software package called 'VP-Planner plus', from Paperback Software, which we have been using for many years; this package offers a cheap solution to the problem by utilizing its 'Multi-dimensional Database' TM files. The great advantage is in the user interface which is almost identical to Lotus 1-2-3 TM. Consequently most spreadsheet users will already be familiar with the command sequences and macro language. The worksheet files are also compatible with versions $1 \mathrm{a}$ and $2 . x$ of $1-2-3$ and therefore can be imported into most statistical and graphics packages.

Setting up a Multi-dimensional Database requires a degree of forethought as the structure of the files are rigid and are difficult or impossible to alter once in place. The structure can consist of up to five dimensions, for example a 
multi-centre clinical trial (1) involving two or more doses of drug (2), sample times, with plasma drug concentrations (3), phase (4) and subjects $(5)$.

The computer screen can only display two dimensions (or 'slice' of the file) at any time but with this software the worksheet can be set up to display views through the various fields and perform consolidations of the data automatically via logic statements built into the Multidimensional Database structure or directly on the screen. A large number of keystrokes are required for these various activities but with the judicious use of macros many of the tasks can be performed by one or two key presses.

This demonstration will illustrate the ability of the system to store, manipulate and to carry out statistical analysis of some real pharmacokinetic data in three dimensions namely-phase, subjects, time and concentrations and to produce summary reports and graphics. Several problems encountered when retrieving data, such as the inability to retrieve empty cells resulting in the erroneous calculation of statistics have been overcome with the use of macros and are an integral part of this demonstration. 